\title{
MAPEANDO EL LABERINTO DE LA POLÍTICA PÚBLICA INDÍGENA EN CHILE*
}

\author{
Isabel Aninat \\ Centro de Estudios Públicos \\ Andrés Hernando \\ Centro de Estudios Públicos
}

\begin{abstract}
Resumen: En Chile, desde el retorno de la democracia cada gobierno ha realizado esfuerzos para generar políticas públicas que apunten a resolver los múltiples problemas que afectan a los pueblos indígenas. Sin embargo, estas políticas parecen tener resultados limitados y no alcanzar los objetivos para las que fueron formuladas. ¿Por qué? Este trabajo intenta una respuesta a partir de dos fuentes de información. Primero, realiza una revisión comprehensiva de los programas estatales focalizados en la población indígena. Y segundo, efectúa un análisis de las evaluaciones de programas conduci-
\end{abstract}

Isabel Aninat. Abogada de la Universidad Católica de Chile. Máster en derecho por la Universidad de Columbia. Investigadora del Centro de Estudios Públicos. Email: ianinat@cepchile.cl.

Andrés Hernando. Ingeniero civil en computación por la Universidad de Chile. Doctor en economía por la Universidad de Harvard. Investigador del Centro de Estudios Públicos. Email: ahernando@cepchile.cl.

* Los autores desean señalar: "Para la elaboración de este artículo se tomó como inspiración un informe elaborado por Isabel Aninat para el Banco Interamericano de Desarrollo. Agradecemos la colaboración de Alejandra Concha en la recopilación de información, los útiles comentarios de Slaven Razmilic y Lucas Sierra a una versión inicial y los valiosos comentarios de dos árbitros anónimos de Estudios Públicos. Como es obvio, cualquier error u omisión es de nuestra exclusiva responsabilidad". 
das por la Dirección de Presupuestos (Dipres). Se concluye que la oferta programática efectiva pone en evidencia una notable falta de coordinación entre las instituciones ejecutoras, que rara vez articulan entre ellas las acciones que implementan. Si bien las políticas públicas en materia indígena son, por esencia, multisectoriales, en la práctica han encarnado los peligros de esa multisectorialidad: la dispersión, la fragmentación, la incoherencia y la ausencia de una estrategia general.

PALABRAS CLAVE: política indígena, evaluación, multisectorialidad, descoordinación.

RECIBIDO: noviembre 2018; ACEPTADO: marzo 2019.

\section{MAPPING THE MAZE OF INDIGENOUS PUBLIC POLICY IN CHILE}

ABSTRACT: Since the return of democracy in Chile, each government has made efforts to generate public policies aimed at solving the numerous problems affecting indigenous peoples. However, it seems that these policies have had limited results and have not achieved the objectives for which they were formulated. Why? This paper draws on two sources of information to attempt a response. First, it conducts a comprehensive survey of State programmes targeted at the indigenous population. Second, it analyses the programme evaluations carried out by the Budgetary Affairs Bureau (Dipres). It concludes that the programmes actually delivered are very poorly coordinated between the implementing institutions, which rarely consult with one another on the actions they carry out. Public policy on indigenous issues is multisectoral by its very nature, and in practice it has come to embody the dangers of this multisectorality: dispersion, fragmentation, inconsistency and the lack of an overarching strategy.

KEYwords: indigenous policy, evaluation, multisectorality, lack of coordination.

ReCEIVED: November 2018; ACCEPTED: March 2019. 
Se necesitan reformas que aseguren - entre otras cosasque los pueblos indigenas puedan nuevamente confiar en un sistema que les ha fallado con demasiada frecuencia en el pasado (...). Después de todo, no es que seamos el primer gobierno en reconocer la necesidad de cambio y promete que hará las cosas de una forma diferente. (...) Ahora imaginen la decepción que se acumula - la esperada y conocida desazón y la creciente acumulación de rabia - cuando el gobierno que ha prometido tanto hace tan poco por respetar su palabra.

Declaración del Primer Ministro de Canadá, Justin Trudeau, en la Casa de los Comunes, a propósito del Marco de Reconocimiento e Implementación de Derechos, 2018.

\section{INTRODUCCIÓN}

a aprobación de la Ley 19.253 en 1993, conocida como la Ley Indígena, es uno de los principales hitos de nuestra historia en materia indígena. Ella, entre otras cosas, creó la Corporación Nacional de Desarrollo Indígena (Conadi) como un organismo descentralizado, al alero del entonces Ministerio de Planificación, cuya dirección está a cargo de un Consejo Nacional ${ }^{1}$. Desde entonces, la Conadi ha sido la institución más relevante en Chile en materia de diseño e implementación de política indígena.

El artículo 39 de la ley establece que la Conadi es la encargada de promover y coordinar, en su caso, la acción del Estado a favor del desarrollo integral de las personas y comunidades indígenas, además de otras funciones. Su Consejo Nacional debe definir la política de la institución y velar por su cumplimiento. A este mandato legal se suma la obligación que la Ley 20.530 le otorga al Ministerio de Desarrollo Social (MDS) - institución que supervigila a la Conadi - de velar por

${ }^{1}$ Este consejo está integrado por el director nacional, nombrado por el Presidente de la República, cinco subsecretarios o sus representantes (Segegob, MDS, Minagri, Mineduc y BB.NN.), tres consejeros determinados por el Presidente de la República y ocho consejeros elegidos por los pueblos indígenas (cuatro mapuches, un aimara, un atacameño, un rapanuí y un indígena de un área urbana del territorio nacional). 
la coordinación, consistencia y coherencia de los programas, políticas y planes en materia de equidad y desarrollo social. ${ }^{2}$

Otro gran hito en materia indígena fue la ratificación en 2008 del Convenio 169, sobre pueblos indígenas y tribales, de la Organización Internacional del Trabajo (OIT), que entró en vigencia en nuestro país en 2009. El Convenio regula los derechos de los pueblos indígenas en diversas materias, incluyendo tierras, empleo, seguridad social y salud, educación y cultura, y establece los respectivos deberes de los Estados. El aspecto central del Convenio - lo que se ha llamado su corazónes el derecho a consulta de los pueblos indígenas respecto de aquellas medidas administrativas o legislativas susceptibles de afectarlos directamente, regulado en sus artículos 6 y 7.3,4 El Convenio, por ende, establece exigencias y estándares para los Estados en su relación con los pueblos indígenas. Desde su entrada en vigencia, por tanto, las correspondientes políticas públicas dirigidas a las personas indígenas deben entenderse dentro de este contexto normativo.

El presente trabajo busca examinar, entonces, cuál es la realidad actual de las políticas públicas enfocadas en los pueblos indígenas, de manera de analizar si ellas están cumpliendo con el mandato legal de sostener una acción del Estado coordinada y si existe una política indígena propiamente tal. El foco de este artículo está en establecer un diagnóstico respecto a los programas y políticas que llevan a cabo los distintos servicios públicos, caracterizando los programas en forma individual, sus interacciones y coordinaciones, y analizando los resultados de las evalua-

${ }^{2}$ El MDS cuenta, a su vez, con la Unidad de Asuntos Indígenas, que se formó a partir del traspaso del asesor especial para asuntos indígenas que antes dependía del Ministerio Secretaría General de la Presidencia (Segpres). A ello se suma un comité de ministros presidido por el ministro del MDS.

${ }^{3}$ Sobre el proceso de ratificación del convenio, la posterior regulación de la consulta indígena y un análisis de casos, ver De Cea y Peralta (2018).

${ }^{4}$ Hasta la fecha, el Estado ha realizado 76 consultas indígenas, en las que el Ministerio de Obras Públicas destaca como el más activo, con 43 procesos relacionados con el diseño de obras de desarrollo. Lo siguen los ministerios de Desarrollo Social y de Bienes Nacionales, con 6 consultas cada uno; el de Energía, con 5; Educación, con 4, y luego los ministerios de las Culturas, Interior, Medio Ambiente y el Consejo de Monumentos Nacionales, cada uno con 2 consultas. Finalmente, Agricultura, Salud, Economía y Defensa han realizado una consulta cada uno. A esto se agregan 46 consultas realizadas o en desarrollo que forman parte del proceso de evaluación ambiental de proyectos privados. 
ciones a las que (algunos de ellos) han sido sometidos. El objetivo es, por una parte, mostrar las falencias en coordinación y en sistematización de la oferta pública y, por otra, contribuir a iluminar la discusión respecto al diseño de política pública y oferta programática en materia indígena.

Dado lo anterior, en el análisis en este documento no se incluyen las demandas políticas de los pueblos indígenas ni sus discusiones constitucionales. El examen que se presenta a continuación servirá para dar luces respecto a los desafíos y problemas que se presentan actualmente para informar el diseño e implementación de una futura institucionalidad de y para los pueblos indígenas.

Menos de una década después de la aprobación de la Ley Indígena, la Comisión de Verdad Histórica y Nuevo Trato ${ }^{5}$ ya manifestó una preocupación por el organismo a cargo de las definiciones y la ejecución de las políticas públicas indígenas, la forma de velar por su pertinencia e impacto, y las instituciones representativas de los pueblos indígenas (Comisión de Verdad Histórica y Nuevo Trato 2003). Desde entonces se ha sucedido una serie de iniciativas para modificar la actual institucionalidad de y para los pueblos indígenas. Las propuestas concretas han variado entre los distintos gobiernos, yendo desde una subsecretaría en el entonces Ministerio de Planificación (actual MDS) hasta los proyectos de ley en discusión legislativa todavía al momento de escribir este artículo, que crean el Ministerio de Pueblos Indígenas (Boletín 10.687-06) y, en paralelo, el Consejo y los Consejos de Pueblos Indígenas (Boletín 10.526-06).

La recurrencia de estas propuestas da cuenta de que la institucionalidad original ha demostrado no ser suficiente en una serie de aspectos. Se han dado razones políticas para su cambio, y también se ha sugerido como una manera de mejorar las formas de relación entre el Estado y los pueblos indígenas (ver, por ejemplo, los mensajes de los proyectos de ley referidos).

Existen también razones relativas al funcionamiento al interior del Estado. Las políticas públicas en relación con la población indígena se enfocan en los múltiples ámbitos que forman parte de la realidad de los pueblos indígenas en nuestro país. Son, por tanto, multisectoriales. Sin

${ }^{5}$ La Comisión de Verdad Histórica y Nuevo Trato fue creada por decreto supremo el 18 de enero de 2001 por el entonces Presidente Ricardo Lagos Escobar. Encabezada por el ex Presidente Patricio Aylwin Azócar, estaba formada por 26 comisionados, representantes de la academia, la política y los pueblos indígenas, y entregó su informe final el 28 de octubre de 2003. 
embargo, como se ilustrará a lo largo de este artículo, han caído en los principales riesgos que implica la multisectorialidad: la dispersión, la fragmentación, la incoherencia y la ausencia de una estrategia general. La cuestión sobre qué herramientas son necesarias para abordar esta realidad es crucial para una futura institucionalidad.

Este trabajo se estructura de la siguiente manera. En la segunda parte se presenta una caracterización de la población indígena en Chile, luego se presenta una revisión de literatura en que se incluyen ejemplos de los esfuerzos principales de otros países que han avanzado en la línea de generar coordinación y políticas sistémicas en materia indígena. En las tres secciones siguientes se presenta el panorama de las políticas públicas indígenas en Chile. La sección IV realiza un breve recuento sobre los intentos de crear políticas estratégicas generales desde 1990 hasta 2018. En la sección V se presenta un mapeo de la realidad actual de los programas públicos que dicen relación con los pueblos indígenas. Y la siguiente sección (VI) hace referencia a las evaluaciones existentes sobre la efectividad de estos programas. Posteriormente, en la sección VII, se aborda la pregunta de cómo dotar a la institucionalidad de herramientas para hacerse cargo del diagnóstico presentado, para así discutir en detalle si las propuestas legislativas actualmente en debate son suficientes. En la última parte se concluye con recomendaciones de política pública para crear una política indígena sistémica.

\section{BREVE CARACTERIZACIÓN DE LA POBLACIÓN INDÍGENA}

En el año 2017, en base a la Encuesta de Caracterización Socioeconómica (Casen), el 9,5 por ciento de la población declaró pertenecer a uno de los nueve pueblos indígenas reconocidos por ley, lo que equivale a 1.694 .870 personas. La declaración de pertenencia a un pueblo indígena ha ido creciendo desde el año 2006, cuando alcanzaba el 6,6 por ciento. El pueblo mapuche ${ }^{6}$ se ha mantenido como la etnia de mayor tamaño, alcanzando actualmente el 84,8 por ciento de las personas

${ }^{6}$ En este trabajo, el término "mapuche" se usa como un vocablo integrado al castellano; es decir, con el uso del plural. Entendiendo que sobre esa palabra hay distintas posiciones, se ha optado por el vocablo en castellano ("mapuche", "mapuches"), sin que dicha opción responda a una decisión política. Se conservará el uso de mapuche como plural cuando en una cita esté empleado así. 


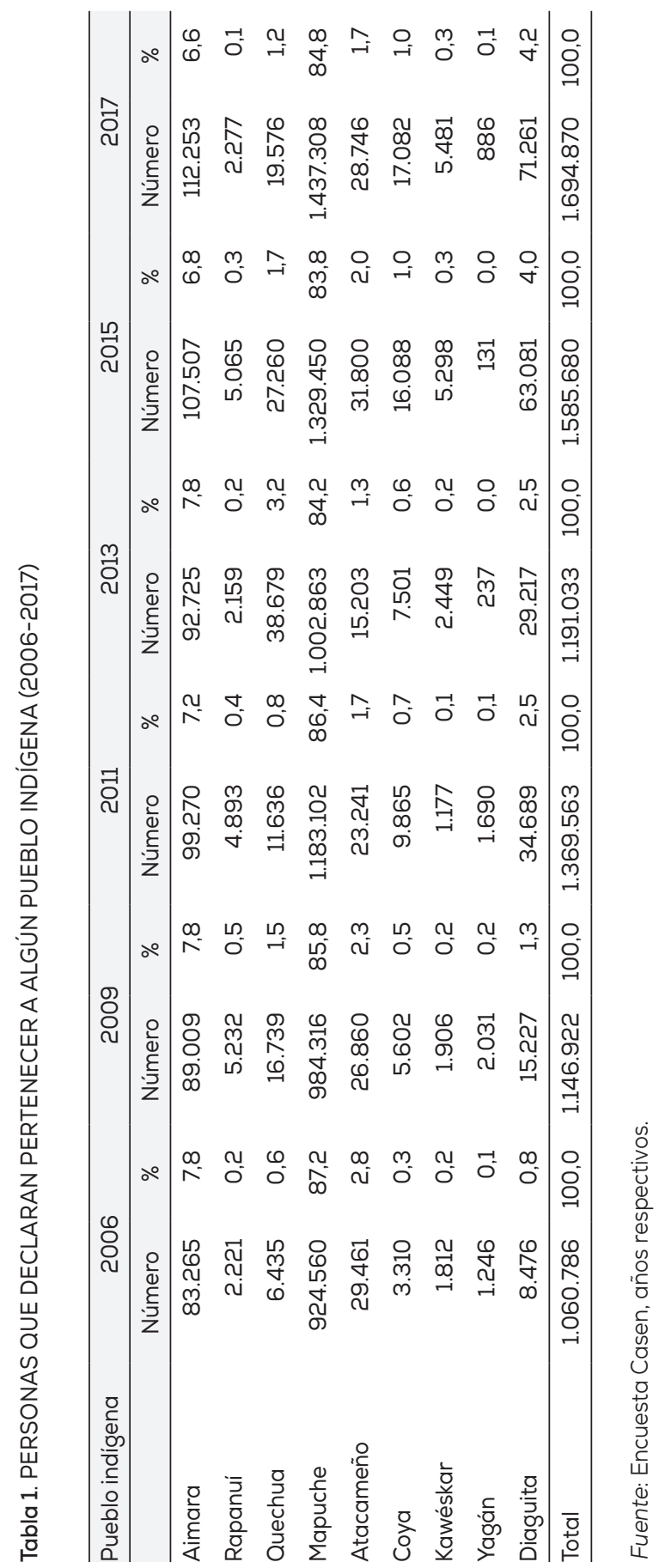


indígenas, mientras que los pueblos de menor tamaño son el pueblo kawéskar ( 0,3 por ciento), el rapanuí $(0,1$ por ciento) y el yagán $(0,1$ por ciento). El pueblo que ha experimentado mayor crecimiento desde el año 2006 es el diaguita, pasando de 8.476 personas ( 0,8 por ciento) a 71.261 (4,2 por ciento) (ver tabla 1).

La población indígena todavía presenta mayores tasas de pobreza respecto de la población no indígena. La encuesta Casen 2017 muestra que, si bien la pobreza se ha reducido considerablemente desde el año 2006 para la población indígena, el 10,5 por ciento de ella vive en pobreza no extrema y el 4 por ciento en pobreza extrema (ver gráfico 1). Asimismo, la tasa de reducción de pobreza fue mayor para la población no indígena, lo que muestra que se mantiene un rezago importante del impacto del gasto social para la población indígena. Bajo la medición de pobreza multidimensional, nuevamente, a pesar de la reducción considerable en los últimos años, en 2017 la población indígena también presentaba mayores tasas que la población no indígena: 30,2 y 19,7 por ciento, respectivamente.

Respecto de la situación laboral, la tasa de desocupación de las personas indígenas se ha mantenido más alta que la de la población no indígena: en 2017, 8,3 versus 7,8 por ciento, respectivamente. En cuanto a la educación, si bien ha crecido en los últimos años, se mantiene la brecha del promedio de escolaridad de las personas pertenecientes a los pueblos indígenas respecto de las personas no indígenas, teniendo el año 2017 casi un año menos de escolaridad promedio.

Pero la realidad de los pueblos indígenas en Chile es aún más compleja. Además de los aspectos socioeconómicos, existen temas asociados a la identidad y las lenguas propias. Tanto la encuesta "Los mapuche rurales y urbanos hoy" - del Centro de Estudios Públicos (CEP), llevada a cabo en 2006 y en 2016-, como el "Estudio longitudinal de relaciones interculturales" - del Centro de Estudios Interculturales e Indígenas (CIIR), de 2017, que incluye al pueblo mapuche y a los pueblos andinos - muestran que la identidad étnica convive con la identidad nacional, predominando el sentido de identidad mixta (ver gráfico 2). Por lo mismo, el matrimonio de una persona indígena con una persona no indígena no es problemático; por el contrario, el matrimonio mixto es común en la sociedad chilena. ${ }^{7}$

${ }^{7}$ Para una mayor problematización sobre el sentido de identidad indígena actual, especialmente en el contexto urbano, ver Walter Imilán (2017). 


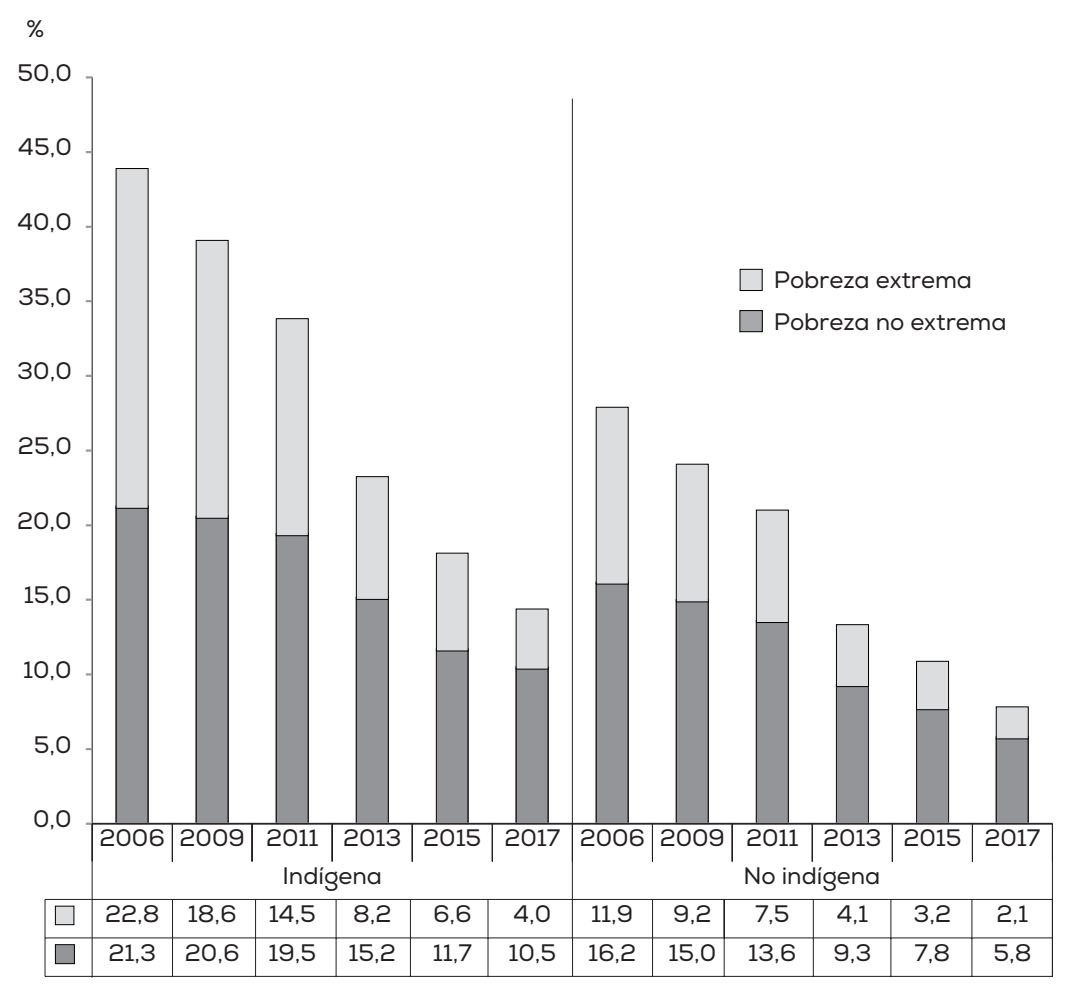

Fuente: Encuesta Casen, años respectivos.

Hay distintas razones que explican la predominancia de la identidad mixta, una de ellas es la migración de la población indígena a centros urbanos. El caso del pueblo mapuche, mayoritario en el país, es ilustrativo. Como muestran los datos de la encuesta Casen, mientras que en 1996 el 46 por ciento de quienes se autoidentificaban como mapuches residía en zonas urbanas, en 2017 esa cifra alcanza al 73,3 por ciento. En la actualidad, además, esa migración ya no responde únicamente a razones económicas asociadas a la tierra, sino que también a un fenómeno de atracción de los centros urbanos que dice relación con mejores posibilidades de empleo y, especialmente, educación (Valenzuela y Araniz 2018). Asimismo, ese proceso se ha acelerado en los últimos años, con una población mapuche que se mantiene prácticamente estancada a nivel rural, al tiempo que vive un aumento significativo en zonas urbanas desde el año 2009, fenómeno especialmente acentuado a partir de 2013. Por lo mismo, 


\section{Gráfico 2. IDENTIFICACIÓN INDÍGENA VERSUS IDENTIFICACIÓN NACIONAL}

En general, ¿usted se siente más bien chileno,
pueblo originario o una mezcla de los dos?

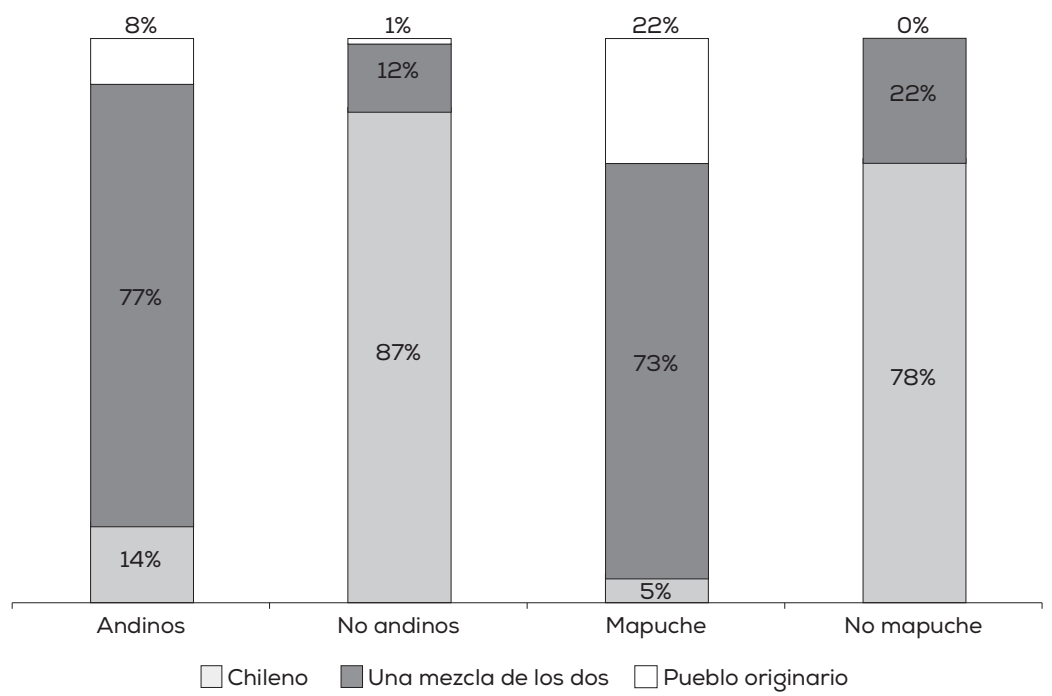

Fuente: "Estudio longitudinal de relaciones interculturales" (CIIR 2017).

hoy la población mapuche ya no se concentra en La Araucanía (22,8 por ciento), sino que en la Región Metropolitana (32,2 por ciento).

Nuevamente, el pueblo mapuche es ilustrativo de lo que ocurre con las lenguas indígenas. ${ }^{8}$ Según la citada encuesta CEP, el pueblo mapuche considera hablar el mapuzugun como la característica más

${ }^{8}$ No existen encuestas comparables a la del Centro de Estudios Públicos para otros pueblos. Sin embargo, la encuesta Casen ha preguntado por el manejo de la lengua en un periodo similar, aunque con preguntas que no son estrictamente comparables con las consideradas por el CEP. En 2006 la pregunta fue: “¿Algún miembro del hogar habla o entiende alguna de las siguientes lenguas: aimara, rapanuí, quechua, mapudungún, kawéskar o yagán?”, y en 2017: “¿Habla o entiende algunas de las siguientes lenguas: aimara, rapanuí, quechua, mapudungún, kawéskar o yagán?". En ambos años las respuestas podían ser "Habla y entiende"; "Sólo entiende"; "No habla ni entiende". De responder una de las primeras alternativas, se preguntaba por la lengua específica. Analizando estas respuestas para aquellos grupos que tienen muestra suficiente se aprecia que, en el periodo de 2006 a 2017, los miembros del pueblo aimara que tienen algún dominio de su lengua disminuyeron del 26,3 al 22,1 por ciento; los del pueblo quechua bajaron del 57,6 al 28,8 por ciento. En último caso, es importante recordar el gran crecimiento de la autoidentificación con este pueblo en el periodo (ver tabla 1). 
importante para definir a una persona como mapuche, por sobre la cantidad de apellidos mapuches, la participación en ceremonias tradicionales o el vivir en las tierras mapuches. A pesar de ser crucial para conservar y mantener viva su cultura, las cifras revelan un creciente abandono del aprendizaje y uso del mapuzugun. Entre los años 2006 y 2016 el número de mapuches que afirma no hablar ni entender la lengua creció en 12 puntos porcentuales, y si bien en zonas rurales aquellos que declaran hablarlo con algún grado de competencia llega al 33 por ciento, diez años atrás esa proporción llegaba al 40 por ciento. ${ }^{9}$ Incluso, entre aquellos que afirman tener conocimiento, el uso cotidiano del mapuzugun es minoritario y, más preocupante aún, no se usa para comunicarse con niños pequeños, aspecto crucial para la transmisión de la lengua y la conservación de la cultura. ${ }^{10}$

\section{EXPERIENCIA COMPARADA}

Los desafíos de coordinación y sistematización de la oferta pública para la población indígena no son exclusivos de Chile. A nivel comparado, existen varios ejemplos de países que han intentado dar una mirada sistémica a las políticas públicas sectoriales para los pueblos indígenas. Entre otras razones, porque la política indígena ha sido clasificada como un "problema complejo" (wicked problem), dado que se trata de un tema social altamente complejo, en que influyen múltiples causas y existen interdependencias, con consecuencias que no siempre se pueden prever, para el que no existe una solución clara y única, y respecto del cual los programas fracasan casi crónicamente. Desde la perspectiva de la gestión pública, el llamado ha sido entonces a establecer una visión de gobierno integrado (whole of government), en que prime la acción coordinada de diversos servicios públicos, bajo una estrategia de marco común, que pueda implementarse en los diversos niveles del Estado y

${ }^{9}$ Respuesta a la pregunta: “¿Con qué facilidad diría Ud. que habla la lengua mapuche?" Las alternativas de respuesta son: "Mejor que el castellano", "Igual que el castellano", "Peor que el castellano", "La entiendo pero no la hablo" y "No la hablo ni la entiendo". En el año 2006, para el total de la muestra, las tres primeras alternativas representaban el 24 por ciento de las respuestas. Este porcentaje cayó al 15 por ciento en 2016 .

${ }^{10}$ Para mayores detalles sobre la situación de la lengua mapuche en Chile, ver Zúñiga y Olate (2017). 
rompa con la lógica parcializada y vertical del aparato público (Australian Public Service Commission 2007). ${ }^{11}$

Por lo mismo, a nivel comparado, y particularmente en el mundo anglosajón, existen varios ejemplos de informes o revisiones que buscan aproximarse a la política indígena con una mirada transversal.

Quizás el caso más avanzado en estos términos es Australia, país que en el año 2007 estableció, mediante el Council of Australian Governments (COAG), ${ }^{12}$ la política de largo plazo Closing the Gap, que definió indicadores para objetivos en seis áreas: expectativa de vida, mortalidad infantil, primera infancia, alfabetización, educación y empleo. El monitoreo de los avances respecto de dichos objetivos se materializa periódicamente en tres informes: un reporte anual del Primer Ministro al parlamento, un reporte bianual de la Comisión de Productividad y un reporte anual del propio COAG.

El último reporte del Primer Ministro se centra en las lecciones aprendidas a diez años de que se estableciera la política Closing the Gap, valorándola en cuanto ha permitido mantener un foco colectivo, incluyendo análisis transversales — como la necesidad de una mirada holística, el involucramiento de las comunidades, la colaboración entre agencias, la necesidad de planificación y evaluación de programas, la capacitación de los funcionarios, etcétera-, así como sectoriales para los indicadores establecidos y para los territorios (Department of the Prime Minister \& Cabinet 2018). Por su parte, el último reporte bianual de la Comisión de Productividad incluye un análisis de datos respecto de los seis indicadores, pero hace un llamado a que el uso de los datos debe considerarse como un instrumento que sirva para informar al gobierno en su acción política y a las comunidades indígenas para exigir más responsabilidad (accountability). El reporte no hace una evaluación

${ }^{11}$ El enfoque de gobierno integrado surge en el contexto de las críticas a los niveles de fragmentación y desagregación de la administración pública, producto, entre otros, de reformas de la llamada Nueva Gestión Pública. Como respuesta a dichos problemas, tanto desde el mundo académico (por ejemplo, Christensen y Lægreid, 2007), como desde los propios gobiernos (por ejemplo, Tony Blair en Inglaterra y su llamado al joined-up government, o en Australia con el connecting government) se ha planteado un nuevo enfoque integral, con el objetivo de mejorar la coordinación y la colaboración en el actuar del Estado.

12 Para mayores detalles sobre la creación del COAG, la gobernanza colaborativa y su impacto en la política indígena en Australia, especialmente en la década de los 2000, ver O'Flynn (2018). 
en profundidad de programas específicos, sino que presenta información para hacer seguimiento y evaluar los progresos a nivel transversal (Productivity Commission 2016).

A esos reportes se suman otros informes como los que prepara la Comisión de Productividad en materia de gasto público en políticas públicas indígenas y los que han publicado ministerios sectoriales. Uno de esos informes sectoriales es particularmente interesante. En el año 2009, el Ministerio de Finanzas de Australia llevó a cabo una revisión estratégica del gasto público en materia indígena, cuyo objetivo era analizar posibles redirecciones hacia programas exitosos o la consolidación de ciertos programas, evitando la duplicación o el mantenimiento de políticas mal evaluadas. De la revisión de los 232 programas que componían la política indígena, el informe concluyó, entre otros, que el progreso en esta materia ha sido, en el mejor de los casos, mixto y que uno de los principales desafíos era la efectiva implementación y ejecución de los programas. Asimismo, explicitó que el panorama general de los programas indígenas era particularmente confuso y complejo, con mucha duplicación y fragmentación, poca articulación y una particular falta de datos y evidencia respecto de su funcionamiento y resultados. El informe incluye también el análisis de los programas por áreas: primera infancia, educación, juventud, salud, desarrollo económico, vivienda, familia y comunidades, institucionalidad y temas de política pública en general (Department of Finance and Deregulation 2010).

En Nueva Zelandia, a raíz del establecimiento en el año 2012 de la política transversal Better Public Services, ${ }^{13}$ el ministerio para asuntos indígenas Te Puni Kokiri ha llevado a cabo evaluaciones para analizar cuál es la situación de los maoríes respecto de los indicadores ahí establecidos. Dado que Te Puni Kokiri cumple el rol de asesorar a los demás ministerios y agencias respecto de las políticas indígenas, ha realizado informes que buscan diferenciar y comparar los resultados que presentan los maoríes en relación con la población en general en cada área. Entre otras cosas, dichos informes han alertado también so-

${ }^{13}$ Se establecieron diez indicadores en base a cinco áreas: reducción de la dependencia de largo plazo ayudas estatales, apoyo a niños vulnerables, capacitación y empleo, reducción de la criminalidad, y mejoramiento de la interacción con el Estado. 
bre problemas en la recolección de datos respecto de los maoríes y han levantado objetivos específicos para los distintos ministerios y agencias, buscando mayor efectividad de las políticas indígenas (Te Puni Kokiri 2014; 2017).

Otro ejemplo de una mirada transversal sobre la política indígena es el que ha llevado a cabo el gobierno canadiense. En febrero de 2017, el Primer Ministro estableció un grupo de trabajo de ministros para revisar las leyes, políticas y prácticas de ejecución que dicen relación con los pueblos indígenas, ${ }^{14}$ con el objetivo de asegurarse de que estén conforme al reconocimiento de derechos y avanzan hacia la reconciliación, en base a los Principios del Gobierno de Canadá en su relación con los pueblos indígenas. ${ }^{15}$ Por su parte, la institución estatal Indigenous Services tiene como parte de su mandato actual identificar modelos para mejorar la entrega de servicios públicos a los pueblos indígenas y mejorar la responsabilidad (accountability) al respecto.

A nivel latinoamericano, es interesante el esfuerzo que lleva a cabo la agencia de evaluación mexicana Coneval, que, además de evaluar en profundidad programas específicos, realiza evaluaciones transversales por áreas, incluyendo la población indígena. Por ejemplo, en la evaluación integral de 2012-2013, se incluyó el desempeño de ocho programas llevados a cabo por dos instituciones, buscando interpretar los resultados en un contexto más amplio que cada programa en sí mismo, analizando, por ejemplo, las complementariedades y sinergias existentes y los desafíos comunes (como la identificación de las poblaciones objetivos) (Coneval 2013). Anteriormente, la agencia había centrado su evaluación integral en una institución en particular, analizando la Comisión Nacional para el Desarrollo de los Pueblos Indígenas (CDI) y todos los programas que de ella dependen, de forma de dar un panorama integrado de la institución y su funcionamiento, no en cuanto a procesos internos, sino en cuanto diseñador y ejecutor de políticas públicas (Coneval 2012).

14 Integraron el grupo de trabajo los ministros de las relaciones entre la Corona y los Pueblos Indígenas; Recursos Naturales; Familias, Niños y Desarrollo Social; Pesca, Océanos y Guardia Naval; Servicios Indígenas y Justicia.

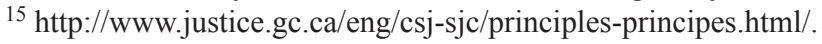




\section{LOS INTENTOS DE POLÍTICAS INDÍGENAS DESDE 1990 HASTA 2018}

En Chile, desde el Acuerdo de Nueva Imperial (1989) ${ }^{16}$ y el regreso a la democracia, cada gobierno ha anunciado sus propias políticas indígenas. Han sido intentos por establecer políticas estratégicas generales que abarcan una mirada multisectorial de la acción del Estado sobre los pueblos indígenas. En algunos casos, esto se ha realizado mediante planes o políticas especiales, mientras que en otros se ha cristalizado por medio de conformación de comisiones asesoras. Es interesante que estos esfuerzos se han realizado al margen de la Conadi, a pesar de su mandato legal de llevar a cabo la política indígena, demostrando que ésta no ha cumplido un rol articulador ni estratégico al respecto.

En general, todas las políticas transversales se han enfocado en cinco áreas: reformas constitucionales y políticas, institucionalidad, programas sociales (educación, cultura y salud), fomento productivo y tierras. Algunas políticas han sido comprehensivas para todos los pueblos indígenas, mientras que otras se han centrado particularmente en la región de La Araucanía.

La tabla 2 presenta un catastro de las políticas indígenas desde 1989 hasta 2018. Si bien con la vuelta a la democracia los anuncios se concentraron en la aprobación y puesta en práctica de la Ley Indígena y su institucionalidad asociada, con los años empezaron a extenderse a las otras áreas señaladas. Como se ve, desde el año 2000 en adelante, momento en que se torna más compleja la relación del Estado con los pueblos indígenas, dichos anuncios han aumentado.

La revisión de las políticas y anuncios muestra que, salvo excepciones particulares, ${ }^{17}$ suelen repetirse los mismos anuncios para las distintas áreas, sin observarse grandes distancias entre ellos, especial-

${ }^{16} \mathrm{http}: / / w w w . p o l i t i c a s p u b l i c a s . n e t / p a n e l /$ biblioteca/doc_view/21-acuerdo-denueva-imperial-1989.raw?tmpl=component/.

${ }^{17}$ La CEPI se diferencia de las otras comisiones en cuanto tuvo por encargo la discusión de futuros proyectos de ley, incluyendo la Ley Indígena. Respecto de las otras comisiones y políticas, una excepción, por ejemplo, es la propuesta de reposición de las actividades económicas que resulten afectadas por eventos de violencia rural, contenida en el Plan de Reconocimiento y Desarrollo Araucanía, en base a la propuesta de reparación de víctimas de violencia en la región de la Comisión Asesora Presidencial de La Araucanía ("Comisión Vargas"). 
Tabla 2. POLÍTICA INDÍGENA SEGÚN GOBIERNO (1989-2018)

\begin{tabular}{|c|c|c|c|}
\hline Gobierno & Nombre & Comisión o plan & Año \\
\hline \multirow[t]{2}{*}{ P. Aylwin } & Acuerdo de Nueva Imperial & Plan & 1989 \\
\hline & $\begin{array}{l}\text { Comisión Especial de Pueblos Indigenas, } \\
\text { CEPI }\end{array}$ & Comisión & 1990 \\
\hline \multirow[t]{2}{*}{ E. Frei } & $\begin{array}{l}\text { Comisión Asesora Presidencial sobre } \\
\text { Desarrollo Indigena }\end{array}$ & Comisión & 1999 \\
\hline & Pacto por el Respeto Ciudadano & Plan & 1999 \\
\hline \multirow[t]{2}{*}{ R. Lagos } & $\begin{array}{l}\text { Comisión Verdad Histórica y Nuevo Trato } \\
\text { con los Pueblos Indigenas }\end{array}$ & Comisión & $2001-2003$ \\
\hline & Políticas del Nuevo Trato & Plan & 2004 \\
\hline \multirow[t]{4}{*}{ M. Bachelet } & $\begin{array}{l}\text { Comisión Asesora sobre Política } \\
\text { Indigena Urbana }\end{array}$ & Comisión & 2006 \\
\hline & Acuerdo Nueva Imperial II & Plan & 2006 \\
\hline & Nuevos ejes de la Política Indiggena & Plan & 2007 \\
\hline & $\begin{array}{l}\text { Re-conocer: Pacto Social por la } \\
\text { Multiculturalidad }\end{array}$ & Plan & 2008 \\
\hline S. Piñera & Plan Araucanía & Plan & $2010-2014$ \\
\hline \multirow[t]{3}{*}{ M. Bachelet } & $\begin{array}{l}\text { Comisión Asesora Presidencial de } \\
\text { La Araucania ("Comisión Vargas") }\end{array}$ & Comisión & 2016 \\
\hline & $\begin{array}{l}\text { Plan de Reconocimiento y Desarrollo } \\
\text { Araucanía }\end{array}$ & Plan & 2017 \\
\hline & Proceso constituyente indigena & Plan & 2017 \\
\hline S. Piñera & $\begin{array}{l}\text { Acuerdo Nacional por La Araucania y } \\
\text { Plan Impulso Araucania 2018-2026 }\end{array}$ & Plan & 2018 \\
\hline
\end{tabular}

Fuente: Elaboración propia.

mente en materia de desarrollo productivo. Esto ha sido particularmente evidente en el reciente Acuerdo Nacional por La Araucanía, el que, en la búsqueda de continuidad y profundización, expresamente destaca que no se partió de cero ni se conformó una nueva mesa de trabajo, sino que se elaboró a partir de lo ya avanzado por las comisiones presidenciales y los planes de desarrollo anteriores (Acuerdo Nacional 2018).

En ciertas áreas los anuncios han sido incrementales y las políticas se orientan a continuar con programas existentes. Ello daría cuenta de que, en la práctica, existe una suerte de política sobre la cual se ha 
seguido construyendo, en base a los mandatos legales establecidos en la Ley 19.253. Las diferencias están principalmente en los énfasis y la forma de presentar los anuncios. Ello se da en particular en dos áreas: tierras y programas sociales. En el caso de la política de tierras y aguas, los gobiernos han continuado con la restitución de tierras bajo la legislación vigente, anunciando o rindiendo cuenta sobre el número de hectáreas. Las novedades han venido de la mano de los énfasis en desarrollo productivo asociado ${ }^{18}$ o en anuncios sobre eventuales reformas a la ley (en especial al establecido bajo el artículo 20 b) de la Ley 19.253. ${ }^{19}$

Respecto de los programas sociales, la continuidad ha imperado, principalmente en base a las áreas determinadas por la Ley Indígena. Por ejemplo, en educación, los gobiernos han continuado y expandido los programas de becas indígenas y educación intercultural, rindiendo cuenta en particular sobre el aumento en el número de beneficiarios y del presupuesto destinado. Esto último se ve en general en los distintos temas: los compromisos han aumentado en especificidad y detalle.

\section{MAPEO DE LAS ACTUALES POLÍTICAS PÚBLICAS PARA LOS PUEBLOS INDÍGENAS}

A continuación se presenta el panorama de los programas que el Estado ofrece a personas pertenecientes a los pueblos indígenas. El catastro fue elaborado en base a las respuestas de los organismos públicos a solicitudes de transparencia efectuadas entre los meses de mayo y agosto de 2018. Es decir, recoge lo que las propias instituciones consultadas informan sobre los programas que implementan en relación con la política indígena, ya sea mediante programas especialmente diseñados

18 Por ejemplo, en el Plan Araucanía 2010-2014 se incluían, además de la regularización de las tierras, objetivos de habitabilidad de tierras traspasadas, de afianzar la seguridad alimentaria y la puesta en producción de las tierras.

${ }^{19}$ Las propuestas más recientes al respecto están contenidas en la Comisión Asesora Presidencial de La Araucanía ("Comisión Vargas") y en el Acuerdo Nacional por La Araucanía (2018). La primera propuso "dictar un nuevo reglamento que con total transparencia regule los mecanismos de compra de tierras del artículo 20 letra b) de la Ley Indígena”. El Acuerdo Nacional propone incentivar el desarrollo territorial mediante la ampliación de la suscripción de contratos de arriendo, mediería o aparcería, la posibilidad de las comunidades titulares de dividir total o parcialmente las tierras, la disminución de los plazos de prohibición de enajenación y la clarificación de las reglas de la permuta para tierras indígenas. 
para los pueblos indígenas o aquellos que atienden a la población en general pero que dan beneficios adicionales para personas indígenas.

En específico, la consulta enviada expresaba:

Solicito información sobre programas o iniciativas del organismo específicamente destinados a personas pertenecientes a pueblos indígenas. En caso de que existan, detallar:

1) Año de creación.

2) Presupuesto 2018.

3) Cobertura.

4) Instrumento de focalización.

5) Zona geográfica cubierta.

6) Descripción de la intervención.

7) Articulación con programas del mismo organismo o de otros ministerios/servicios.

Además, información de programas o iniciativas generales del organismo que otorguen acceso prioritario (por ejemplo, puntaje adicional o líneas diferenciadas) para personas pertenecientes a pueblos indígenas.

En total, la solicitud antes señalada se envió a 314 reparticiones públicas, incluyendo subsecretarías, servicios, corporaciones, direcciones, superintendencias, gobiernos regionales, servicios de salud y hospitales (se excluyeron las municipalidades, el Ministerio de Defensa, el Instituto Nacional de Estadísticas y la Fiscalía Nacional Económica). Se recibió un total de 167 respuestas con información. De las restantes, un número importante de reparticiones contestó no contar con programas con las características señaladas y otra cantidad considerable señaló no contar con la información, pero nos derivó a otras reparticiones que sí la tenían. En total, sólo 5 de las 314 solicitudes no fueron respondidas en forma alguna.

La información así recogida fue luego sistematizada ${ }^{20}$ para la construcción de las tablas e indicadores que se muestran a continuación. Los datos presentados representan el total de la información recibida y sólo a la información recibida. ${ }^{21}$

${ }^{20}$ La tabla final, con toda la información recogida y sistematizada está disponible previa solicitud a los autores.

${ }^{21}$ Por ejemplo, aunque se sabe que existe un programa llamado "Küme mognen pu zomo Ercilla (calidad de vida y autocuidado)" implementado por la Conadi en la comuna de Ercilla, dado que este programa no fue reportado por la institución, 
Desde el punto de vista de los organismos públicos que cuentan con programas o bonificaciones especiales, la política indígena chilena se encuentra distribuida como lo muestra la tabla 3.

Como se puede observar, hay 18 ministerios que implementan, directamente o por medio de alguno de sus servicios dependientes (29 servicios, sin incluir 29 servicios de salud distintos que implementan el mismo programa), algún tipo de programa o que otorgan beneficios particulares para las personas indígenas. Al analizar por el número de programas, el MDS lleva a cabo la gran mayoría, principalmente, aunque no de forma exclusiva, a través de la Conadi. Y si bien, como se señaló anteriormente, el MDS es el ministerio que legalmente debe velar por la coordinación, consistencia y coherencia de las políticas, planes y programas en materia de equidad y desarrollo social, no todos los ministerios involucrados pertenecen al ámbito social, como se evidencia en la tabla 3.

Por otra parte, el Comité de Ministros para Asuntos Indígenas tiene como objetivos velar por la coordinación en la implementación, servir de instancia de evaluación de las políticas, asesorar en fijar las prioridades para el gasto público y sugerir directrices generales para las iniciativas programáticas sectoriales de la política indígena (Art. 2 D.S. 101 de 2010 del Ministerio de Planificación). Parecería ser la instancia, entonces, en que la fragmentación institucional de la política social pudiera mitigarse, y la oferta programática agruparse y coordinarse estratégicamente. Sin embargo, los ministerios involucrados en las políticas indígenas no coinciden exactamente con aquellos que integran el actual Comité de Ministros: MDS, Ministerio del Interior, Secretaría General de la Presidencia (Segpres), Relaciones Exteriores, Educación, Culturas, Bienes Nacionales, Agricultura y Economía. Como se puede obser-

no se encuentra incluido en el análisis presentado, ya que haberlo incorporado habría implicado alterar la información recogida. No incluir un programa que sabemos que existe implica que la información aquí presentada es reconocidamente incompleta. Sin embargo, como no podemos estar seguros de conocer todos los programas que no fueron reportados, incluir los que conocemos implicaría sesgar la muestra en una dirección que no podemos determinar. La misma decisión se adoptó respecto a información específica sobre los programas. Por ejemplo, aunque se sepa de la existencia de una instancia de coordinación o articulación entre instituciones que implementan programas, si estos no reportan dicha articulación, ésta no se incluye en lo que sigue. 
Tabla 3. MINISTERIOS Y SERVICIOS

\begin{tabular}{|c|c|c|}
\hline Ministerio & Servicios relacionados & Abreviatura \\
\hline Bienes Nacionales & & BBNN \\
\hline \multicolumn{3}{|l|}{ Justicia } \\
\hline & Corporación de Asistencia Judicial & CAJ \\
\hline & Defensoria Penal Pública & DPP \\
\hline & Servicio de Registro Civil e Identificación & SRCel \\
\hline \multicolumn{3}{|l|}{ Agricultura } \\
\hline & Comisión Nacional de Riego & CNR \\
\hline & Instituto de Desarrollo Agropecuario & Indap \\
\hline & Oficina de Estudios y Políticas Agrarias & ODEPA \\
\hline \multirow[t]{6}{*}{ Desarrollo Social } & & MDS \\
\hline & Comisión Nacional de Desarrollo Indigena & Conadi \\
\hline & Fondo de Solidaridad e Inversión Social & Fosis \\
\hline & Instituto Nacional de la Juventud & Injuv \\
\hline & Servicio Nacional de la Discapacidad & Senadis \\
\hline & Servicio Nacional del Adulto Mayor & Senama \\
\hline \multicolumn{3}{|l|}{ Educación } \\
\hline & $\begin{array}{l}\text { Comisión Nacional de Investigación Científica } \\
\text { y Tecnológica }\end{array}$ & Conicyt \\
\hline & Junta Nacional de Auxilio Escolar y Becas & Junaeb \\
\hline & Junta Nacional de Jardines Infantiles & Junji \\
\hline \multicolumn{3}{|l|}{ Economía } \\
\hline & Corporación de Fomento de la Producción & Corfo \\
\hline & Servicio de Cooperación Técnica & Sercotec \\
\hline & Servicio Nacional de Turismo & Sernatur \\
\hline Culturas y las Artes & & \\
\hline
\end{tabular}

Deportes

Instituto Nacional del Deporte

IND

Obras Públicas

Dirección de Vialidad

Dirección General de Aguas

DGA

Relaciones Exteriores

Dirección General de Relaciones Económicas Direcon

Internacionales

\begin{tabular}{lll}
\hline Energía & \\
\hline Medio Ambiente & MMA \\
& Servicio de Evaluación Ambiental & SEA \\
\hline
\end{tabular}




\begin{tabular}{lll}
\hline Ministerio & Servicios relacionados & Abreviatura \\
\hline Vivienda y Urbanismo & Minvu \\
& Servicios de Vivienda y Urbanismo & Serviu \\
\hline $\begin{array}{l}\text { Mujer y Equidad de } \\
\text { Género }\end{array}$ & Mujereg \\
\hline
\end{tabular}

\begin{tabular}{lll}
\hline Trabajo & & \\
& Dirección del Trabajo & \\
& Previsión Social & \\
& Servicio Nacional de Capacitación y Empleo & Sence \\
\hline Salud & & Minsal \\
& Servicios de Salud & SS
\end{tabular}

\begin{tabular}{llc}
\hline Interior & $\begin{array}{l}\text { Subsecretaria de Desarrollo Regional y Adminis- } \\
\text { trativo }\end{array}$ & Subdere \\
\hline $\begin{array}{l}\text { Transportes y } \\
\text { Telecomunicaciones }\end{array}$ & MTT \\
& Subsecretaria de Telecomunicaciones & Subtel \\
\hline
\end{tabular}

Fuente: Elaboración propia.

var, no sólo no participan todos, sino que están excluidos ministerios especialmente relevantes desde el punto de vista de la política indígena, como Salud, Justicia y Derechos Humanos y Obras Públicas. ${ }^{22}$

Cabe notar además que el secretario ejecutivo de dicha instancia es el asesor especial para asuntos indígenas, cargo que antes estaba en la Segpres, y que hoy se ha radicado en la Unidad de Asuntos Indígenas del MDS. El artículo 3 del decreto establece que dicha secretaría

${ }^{22}$ Incluso el actual Plan Impulso Araucanía 2018-2026 (que no es exclusivamente política indígena, pero tiene un importante componente como tal) involucra diversos ministerios que no necesariamente coinciden con los anteriores: MDS, Vivienda y Urbanismo, Obras Públicas, Interior, Salud, Agricultura, Educación, Economía, Energía, Medio Ambiente y BB.NN., sumando además expresamente a la Corfo. Este plan fue elaborado por un equipo conformado por dichos ministerios coordinados desde la Intendencia de La Araucanía. En el plan se declara que la convocatoria se hizo para que cada ministerio se comprometiera a darle prioridad a la región y para generar un trabajo intersectorial que permita iniciativas coordinadas y con visión integral, otorgando la coordinación interministerial al intendente "para lograr una acción sinérgica y que el resultado final sea mayor y mejor a la simple suma de las partes realizadas, pero descoordinadas" (Acuerdo Nacional por La Araucanía 2018, 15). 
ejecutiva debe mantener constantemente informado al Comité sobre el estado de avance de las distintas iniciativas comprendidas en la política indígena y que debe proponer criterios que permitan coordinar la gestión intersectorial y efectuar un seguimiento adecuado. La Conadi, como institución, no figura como parte ni del Comité de Ministros para Asuntos Indígenas ni de la secretaría ejecutiva.

Ahora bien, desde el punto de vista del foco de las intervenciones catastradas, una agrupación posible para los programas consiste en las siguientes áreas: fomento productivo, educación y cultura, salud, gestión y participación social, y justicia. Como se verá a continuación, la muestra obtenida sugiere que las políticas públicas indígenas se enfocan principalmente en el área económica, seguida por el área de educación y cultura. En la figura 1 se detallan las instituciones públicas, los programas y sus interacciones para cada área. ${ }^{23}$

Como se puede apreciar en esta figura, existe una amplia dispersión en materia de fomento productivo con foco en la población indígena. Esta área reúne programas que dicen relación con tierras y aguas, así como con trabajo y emprendimiento. Y si bien la Conadi (cuadro oscuro central) es la que implementa los principales programas, por medio de dos fondos principales (Tierras y Agua y Desarrollo Indígena, cuadros más claros, sin numerar), existen trece otras instituciones nacionales (además del Gobierno Regional de La Araucanía, cuadros oscuros) que han llevado a cabo programas o que dan puntaje o acceso prioritario para las personas indígenas. Más interesante aún es la falta de coordinación general entre ellas. Existen instancias de coordinación sectoriales, como se refleja claramente en el caso de la Mesa de Turismo Indígena, pero la Conadi no actúa como un ente coordinador transversal entre todos los organismos involucrados, lo que se refleja en que los programas ejecutados por otras instituciones en general no declaran

${ }^{23}$ En esta figura y en las siguientes los cuadros oscuros indican distintas reparticiones públicas. A éstas se conectan, con línea sólida, los programas que implementan de acuerdo a la información provista. Las flechas punteadas representan las articulaciones que ocurren entre los programas y otras instituciones. En los casos en que se informó la fecha de creación del programa, ésta se incluye en el cuadro respectivo. En el caso de programas que fueron informados, pero que ya no se ejecutan o a los que no se les asigna presupuesto, éstos se etiquetan como concluidos (esto incluye a dos programas que continúan en ejecución pero con fondos asignados en 2017). En la versión digital de este artículo esta figura y las siguientes se publican en alta resolución. 


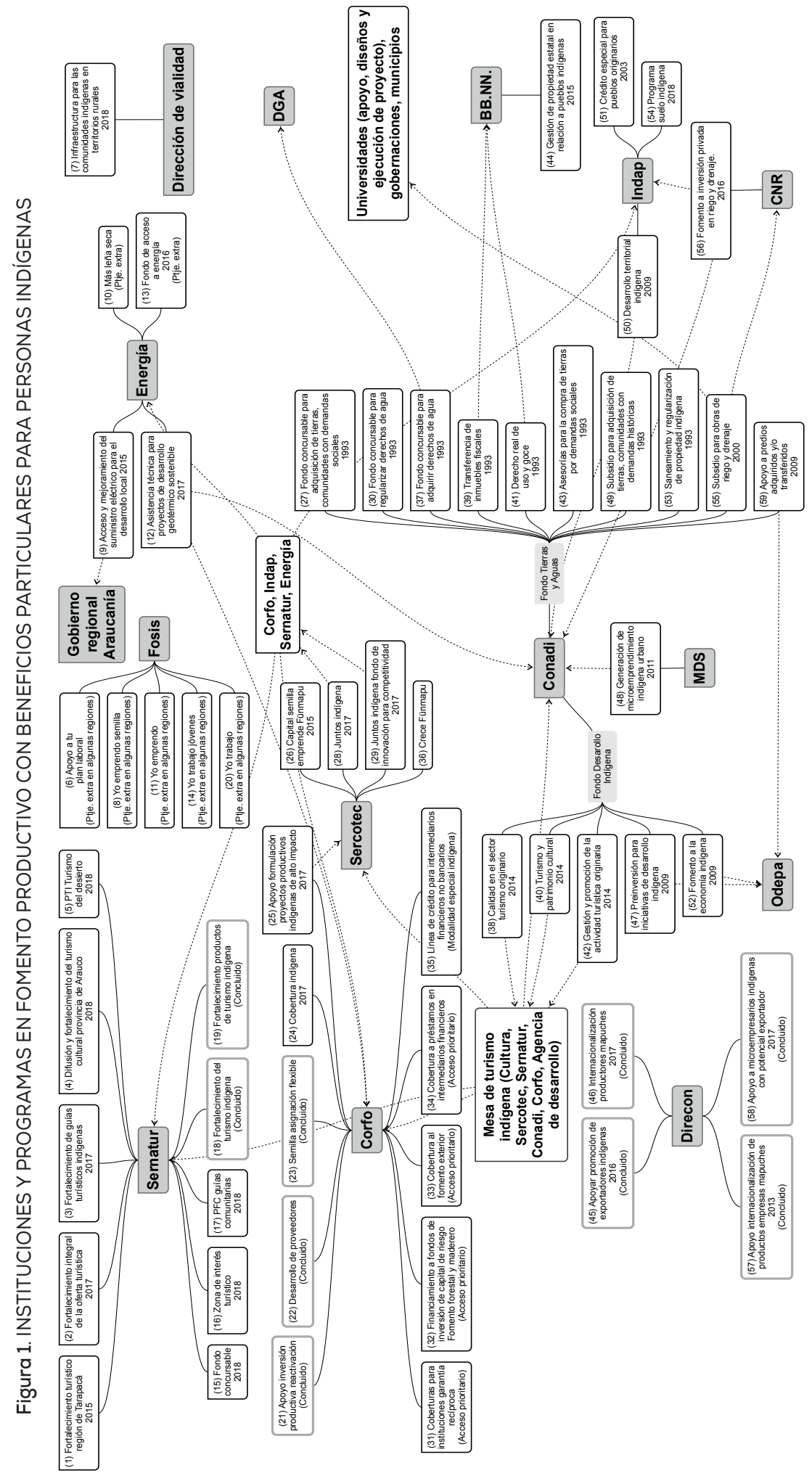


articulaciones con la Conadi (coordinaciones mostradas como flechas punteadas).

En programas con fuertes componentes intersectoriales ha existido mayor preocupación por la articulación transversal. Ello se ha trabajado por medio de la conformación de comités específicos en los que participan representantes de los ministerios y servicios involucrados, como ocurre en el caso de la mencionada Mesa de Turismo Indígena o en el caso de Corfo para sus programas de desarrollo y fomento indígena (programa 25 en la figura 1). Sin embargo, es interesante que dichos comités no parecen estar articulados con el Comité de Ministros para Asuntos Indígenas, supuesta instancia superior de coordinación.

Sin embargo, incluso en programas de alcance relativamente limitado no se reportan coordinaciones que debieran ser evidentes. Tal es el caso, por ejemplo, del programa Suelo Indígena de Indap (número 54 en la figura), que tiene como objetivo apoyar a comunidades indígenas en la recuperación de suelos en la provincia de Osorno y que no indica ningún tipo de articulación con el programa de Conservación y Recuperación del Patrimonio Natural Indígena, el que tiene como fin informar y promover el conocimiento de la normativa ambiental y del impacto de los programas y proyectos que las afectan por parte de la comunidades (ver programa 13 en la figura 4).

La falta de coordinación es aún más dramática en materia de cultura y educación intercultural, ámbito en el que existen 13 instituciones involucradas (cuadros oscuros). En esta área, los programas dicen relación con: (i) preservación y revitalización de las lenguas indígenas, (ii) fomento y difusión de las culturas y (iii) beneficios a estudiantes indígenas. $^{24}$

Como se visualiza en la figura 2, sólo existen seis casos de articulaciones declaradas y se dan únicamente para programas específicos. Considerando, además, que hay programas que tienen objetivos altamente similares, y en los que sería esperable altos niveles de colabora-

${ }^{24}$ Se incluye el programa Gestión Social Indígena (13), que es una iniciativa de habilitación y participación, por cuanto su principal objetivo dice relación con "la expansión de las capacidades de personas y organizaciones indígenas en los ámbitos social, cultural, económico y político a través de la generación de procesos participativos de planificación del territorio". Algunos programas cuyo alcance es lo suficientemente amplio — como en este caso - pueden aparecer consignados en más de un ámbito. 


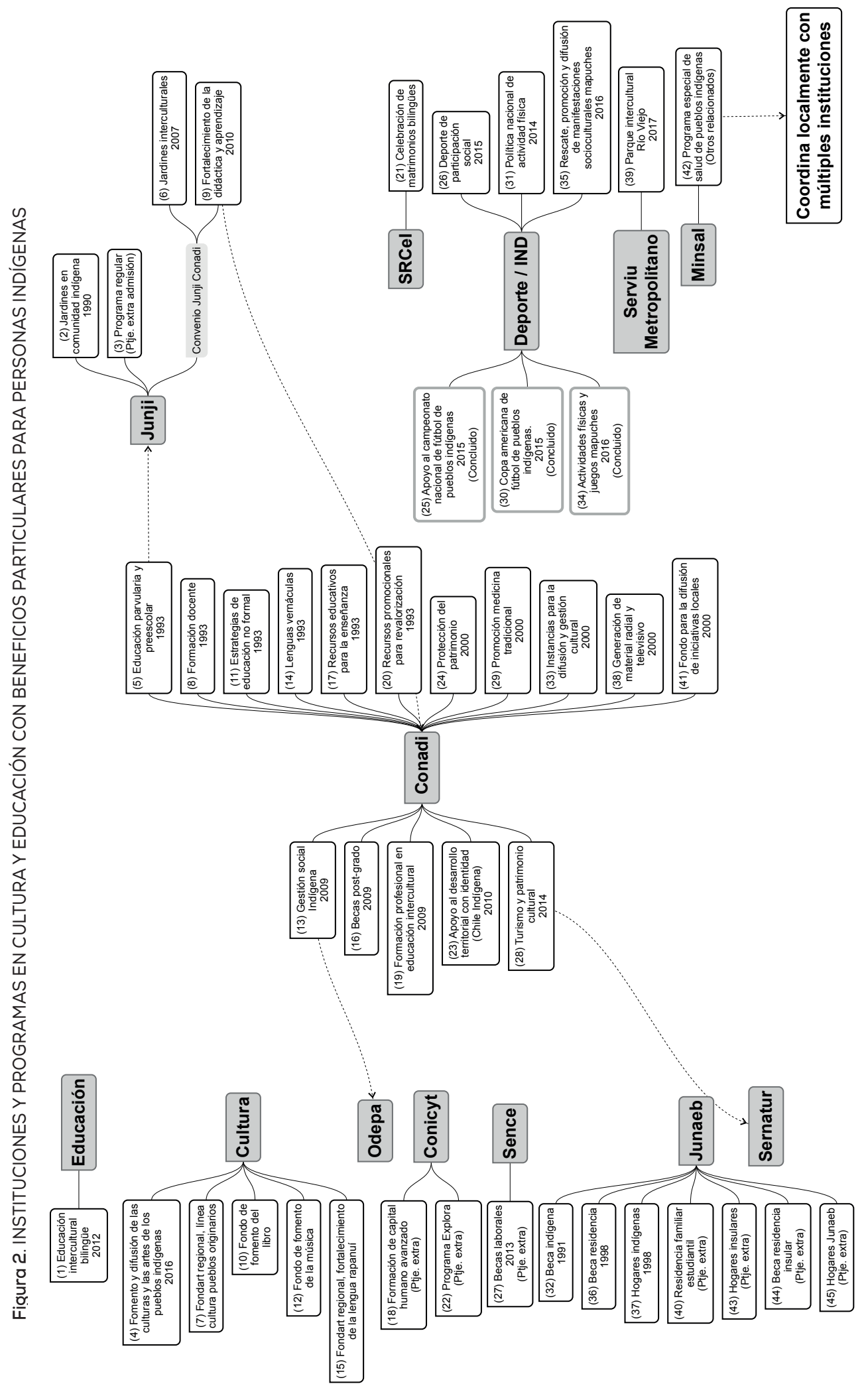


ción, la dispersión es aún más problemática. Un ejemplo es lo que sucede en educación intercultural bilingüe, en que, además de los programas de la Conadi (programas 5, 14, 17, 19 y 20), participan organismos asociados al sector educación: el Ministerio (programa 1), la Junaeb (programa 22) y la Junji (programas 2, 6 y 11). Y aunque sabemos que existen instancias de coordinación (http://peib.mineduc.cl/educacionintercultural-bilingue/), ellas no están siendo reportadas y no es posible evaluar su funcionamiento. La falta de una mirada sistémica en este caso ha llevado, por ejemplo, a que no existe una buena articulación a lo largo del ciclo de vida del estudiante, existiendo diferencias en la definición de la población objetivo y vacíos a lo largo de la educación preescolar y escolar (Dipres 2013).

Llama especialmente la atención el caso de la educación intercultural bilingüe, que busca la preservación y revitalización de las lenguas, puesto que, a pesar de las instituciones involucradas y de la existencia de políticas desde hace ya varias décadas, los programas han mostrado, como se constató en la sección II, ser poco efectivos.

La dispersión existente también refleja un grado importante de improvisación en el diseño de las políticas públicas, ya que se crean programas que tienden a replicar otros ya existentes, sin que se aprecie una mínima coordinación entre ellos. Por ejemplo, existen dos programas cuyo objetivo es el fomento y difusión del arte y las culturas, y cuyas intervenciones son altamente similares, uno de la Conadi (programa 33) y otro del Ministerio de las Culturas (programa 4). Así también, hay programas que dicen relación con áreas en las que ya hay otros programas relevantes en curso y con los cuales no existe articulación o complementación, como es el programa de manejo y protección del patrimonio cultural indígena (Conadi), en que uno de sus componentes es la promoción de la medicina tradicional indígena (programa 29), área en la que existe el programa Especial de Salud y Pueblos Indígenas del Ministerio de Salud - Minsal- (ver figura 3, programa 1).

En el área salud, se vuelve a dar el mismo fenómeno de la falta de articulación global entre distintas instituciones públicas, a pesar de que en este caso hay menos organismos involucrados, como se visualiza en la figura 3. Sin embargo, lo más interesante ocurre al interior del programa Especial de Pueblos Indígenas (1. Pespi). Se trata del programa más importante del área salud, con un presupuesto de 3.552,7 millones 

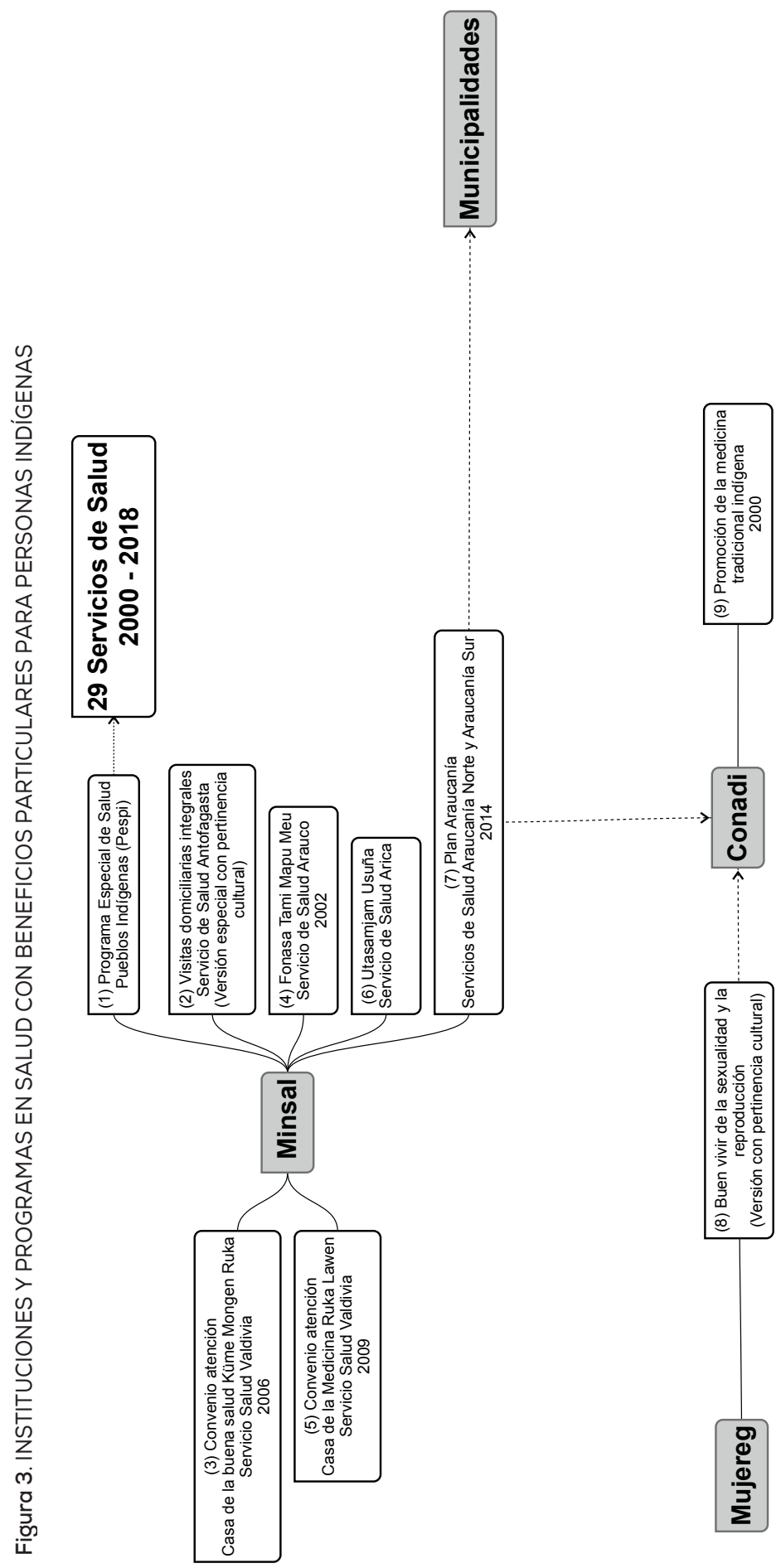
de pesos para el año 2018 y con presencia en los 29 servicios de salud existentes a lo largo del territorio nacional. Al mirar su implementación se evidencian importantes diferencias en la determinación de los beneficiarios que pueden acceder. Según lo declarado por los propios servicios de salud, mientras en algunos el Pespi está abierto a la población indígena y no indígena, en otros sólo se permite el acceso a la población indígena e incluso, en algunos casos, se declara enfocado en pueblos indígenas particulares.

El que cada servicio de salud pueda adaptar ciertos componentes para hacerlos $a d$ hoc a la realidad local parece positivo, pero la diferencia en la determinación de los beneficiarios debiera ser una decisión de política pública común desde el nivel central.

Éste es un problema extendido más allá del área salud. Al revisar la descripción de los programas es posible apreciar que, en general, no se utilizan instrumentos de focalización más allá de la condición de ser indígena, y que los instrumentos para la selección de beneficiarios son muy variables (personas indígenas, comunidades indígenas, comunidades indígenas en una zona geográfica limitada, población indígena y no indígena, etcétera). Según se detallará más adelante, esto se suma a los continuos reparos que la Dirección de Presupuestos del Gobierno de Chile (Dipres) ha levantado respecto de la poca claridad en la identificación y caracterización de la población objetivo, así como respecto del nivel de cobertura de los programas. Bajo este panorama es difícil plantear una política indígena que cuente con análisis más acabados de sus beneficiarios y, a su vez, de la efectividad de los programas en curso.

En materia de gestión y participación social, se mantiene el mismo panorama: abunda la dispersión, existen programas específicos aislados entre sí y la Conadi no parece estar cumpliendo su rol coordinador. Ésta lleva a cabo los programas asociados a sus fondos - Desarrollo Indígena y Medio Ambiente- - pero no existe una estrategia coordinada a nivel general.

Finalmente, en el área de justicia, existen dos servicios que cuentan con atención especializada para personas indígenas. Si bien ambos servicios dependen del Ministerio de Justicia y Derechos Humanos, el enfoque de sus prestaciones es diferente. Sin embargo, llama la atención que la Corporación de Asistencia Judicial (CAJ) no declare algún tipo 


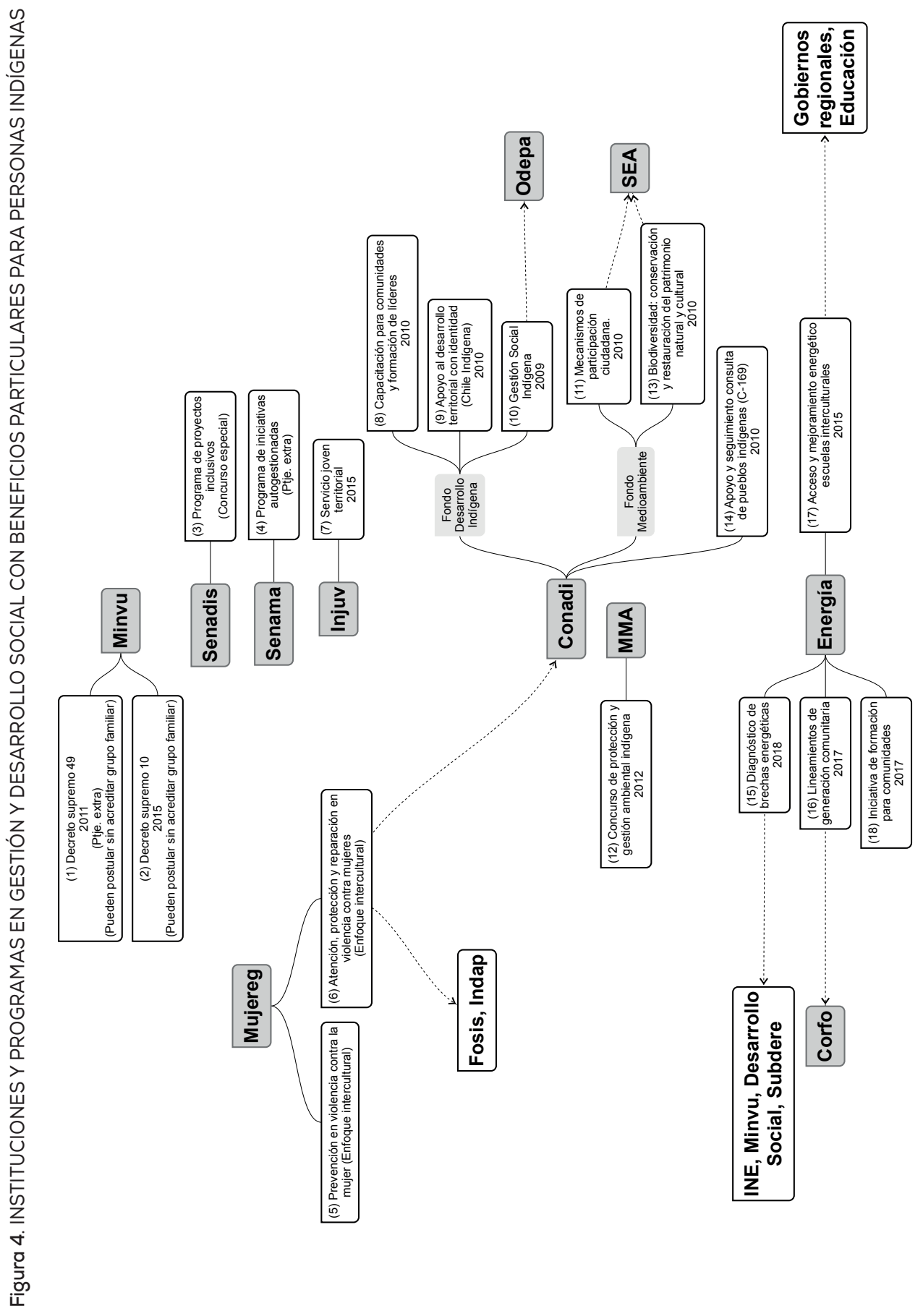


Figura 5. INSTITUCIONES Y PROGRAMAS EN EL ÁREA DE JUSTICIA CON BENEFICIOS PARTICULARES PARA PERSONAS INDÍGENAS

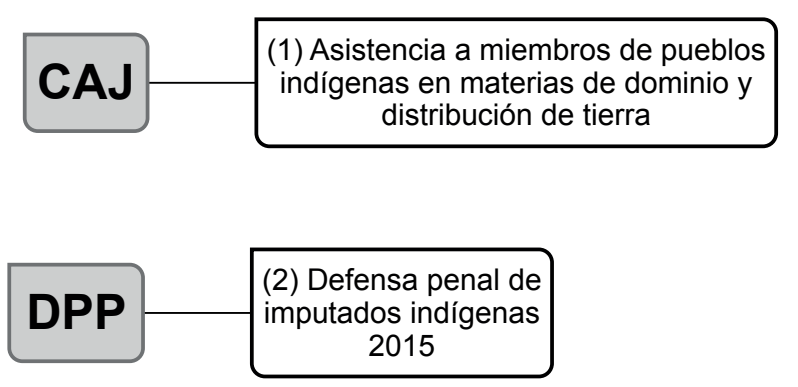

de articulación con la Conadi o con el Ministerio de Bienes Nacionales, a pesar de que se trata de un programa que emana de las normas de dominio y distribución de tierras de la Ley 19.253.

Desde el regreso a la democracia, la política indígena también ha cambiado a lo largo del tiempo. La tabla 4 describe la situación por sí sola.

Como muestra la tabla 4, la creación de los programas indígenas se ha dado con distintos enfoques desde 1990 en adelante. Se evidencia que una primera ola de diseño y puesta en marcha de los programas se dio junto con la aprobación de la Ley Indígena, a principios de la década de los noventa. En ese primer período el enfoque estuvo en la reparación, de la mano del corazón de la Ley Indígena (tierras y rescate cultural). La segunda ola, a partir de los 2000, se centró en educación y cultura y gestión social. La tercera etapa, iniciada principalmente a partir de 2015, se ha concentrado en fomento productivo.

Finalmente, en términos de presupuesto, la figura 6 muestra cómo se distribuye éste por área e instituciones.

Se observa que la mayor parte del gasto $(65,8$ por ciento del total) se destina a fomento productivo seguido por cultura y educación $(26,9$ por ciento) y, en mucho menor grado, gestión y desarrollo social $(4,9$ por ciento del gasto total reportado). Dentro de estas categorías, la mayor parte del gasto en fomento productivo lo representan Conadi $(67,4$ 
Tabla 4. PROGRAMAS QUE BENEFICIAN A INDÍGENAS DESDE EL REGRESO A LA DEMOCRACIA SEGÚN AÑO DE CREACIÓN

\begin{tabular}{|c|c|c|c|}
\hline Área & 1990-1999 & 2000-2009 & $2010-2018$ \\
\hline \multirow[t]{14}{*}{ Fomento } & $\begin{array}{l}\text { Fondo Tierras } \\
\text { Demandas Sociales }\end{array}$ & $\begin{array}{l}\text { Subsidios para Obras } \\
\text { de Riego y Drenaje }\end{array}$ & $\begin{array}{l}\text { Generación de } \\
\text { Microemprendimiento } \\
\text { Indigena Urbano }\end{array}$ \\
\hline & $\begin{array}{l}\text { Asesorias Tierras } \\
\text { Demandas Sociales }\end{array}$ & $\begin{array}{l}\text { Crédito Especial para } \\
\text { Pueblos Originarios }\end{array}$ & $\begin{array}{l}\text { Apoyo Internaciona- } \\
\text { lización de } \\
\text { Productos de } \\
\text { Empresas Mapuche }\end{array}$ \\
\hline & $\begin{array}{l}\text { Fondo Adquisición } \\
\text { Derechos de Aguas }\end{array}$ & $\begin{array}{l}\text { Apoyo a Predios Adqui- } \\
\text { ridos o Transferidos }\end{array}$ & $\begin{array}{l}\text { Calidad en el Sector } \\
\text { Turismo Originario }\end{array}$ \\
\hline & $\begin{array}{l}\text { Fondo Regularización } \\
\text { Derechos de Aguas }\end{array}$ & $\begin{array}{l}\text { Preinversión para } \\
\text { Iniciativas de } \\
\text { Desarrollo Indigena }\end{array}$ & $\begin{array}{l}\text { Turismo y Patrimonio } \\
\text { Cultural }\end{array}$ \\
\hline & $\begin{array}{l}\text { Transferencia de } \\
\text { Inmuebles Fiscales }\end{array}$ & $\begin{array}{l}\text { Desarrollo Territorial } \\
\text { Indigena }\end{array}$ & $\begin{array}{l}\text { Gestión y Promoción } \\
\text { de la Actividad } \\
\text { Turistica Originaria }\end{array}$ \\
\hline & $\begin{array}{l}\text { Derecho Real de Uso } \\
\text { y Goce }\end{array}$ & $\begin{array}{l}\text { Fomento a la Economía } \\
\text { Indigena }\end{array}$ & $\begin{array}{l}\text { Gestión de Pro- } \\
\text { piedad Estatal en } \\
\text { Relación a Pueblos } \\
\text { Indigenas }\end{array}$ \\
\hline & $\begin{array}{l}\text { Subsidio Adquisición } \\
\text { Tierras Demandas } \\
\text { Históricas }\end{array}$ & & $\begin{array}{l}\text { Acceso y Mejora- } \\
\text { miento del Suminis- } \\
\text { tro Eléctrico para el } \\
\text { Desarrollo Local }\end{array}$ \\
\hline & $\begin{array}{l}\text { Regularización } \\
\text { Propiedad Indigena }\end{array}$ & & $\begin{array}{l}\text { Capital Semilla } \\
\text { Emprende Fünmapu }\end{array}$ \\
\hline & & & $\begin{array}{l}\text { Fortalecimiento } \\
\text { Turistico Región de } \\
\text { Tarapacá }\end{array}$ \\
\hline & & & $\begin{array}{l}\text { Fondo de Acceso a } \\
\text { Energía (Ptje. extra) }\end{array}$ \\
\hline & & & $\begin{array}{l}\text { Fomento a Inversión } \\
\text { Privada en Riego y } \\
\text { Drenaje }\end{array}$ \\
\hline & & & $\begin{array}{l}\text { Apoyo Promoción } \\
\text { de Exportadores } \\
\text { Indigenas }\end{array}$ \\
\hline & & & $\begin{array}{l}\text { Fortalecimiento } \\
\text { Integral de la Oferta } \\
\text { Turistica }\end{array}$ \\
\hline & & & $\begin{array}{l}\text { Fortalecimiento } \\
\text { de Guias Turisticas } \\
\text { Indigenas }\end{array}$ \\
\hline
\end{tabular}




\begin{tabular}{|c|c|c|c|}
\hline Área & 1990-1999 & 2000-2009 & $2010-2018$ \\
\hline Fomento (cont.) & & & $\begin{array}{l}\text { Cobertura de } \\
\text { Créditos Indigenas } \\
\text { Apoyo a la Formu- } \\
\text { lación de Proyectos } \\
\text { Productivos Indige- } \\
\text { nas de Alto Impacto } \\
\text { Apoyo a Microem- } \\
\text { presarios con Poten- } \\
\text { cial Exportador } \\
\text { Internacionalización } \\
\text { de Productores } \\
\text { Mapuche } \\
\text { Juntos Indigena } \\
\text { Fondo de Innovación } \\
\text { para Competitividad } \\
\text { Asistencia Técnica } \\
\text { para Proyectos de } \\
\text { Desarrollo Geotér- } \\
\text { mico Sostenible } \\
\text { Difusión y Fortaleci- } \\
\text { miento del Turismo } \\
\text { Cultural, Provincia } \\
\text { de Arauco } \\
\text { PTI Turismo del } \\
\text { Desierto } \\
\text { Fondo Concursable } \\
\text { de Turismo } \\
\text { Zona de Interés } \\
\text { Turistico } \\
\text { PFC Guías } \\
\text { Comunitarias } \\
\text { Programa Suelo } \\
\text { Indigena } \\
\text { Infraestructura para } \\
\text { las Comunidades } \\
\text { Indigenas en } \\
\text { Territorios Rurales }\end{array}$ \\
\hline \multirow[t]{2}{*}{$\begin{array}{l}\text { Cultura y } \\
\text { Educación }\end{array}$} & $\begin{array}{l}\text { Jardines en Comuni- } \\
\text { dades Indigenas } \\
\text { Beca Indigena }\end{array}$ & $\begin{array}{l}\text { Protección del } \\
\text { Patrimonio } \\
\text { Promoción de la } \\
\text { Medicina Tradicional }\end{array}$ & $\begin{array}{l}\text { Apoyo al Desarrollo } \\
\text { con Identidad } \\
\text { Fortalecimiento de } \\
\text { la Didáctica y } \\
\text { Aprendizaje }\end{array}$ \\
\hline & $\begin{array}{l}\text { Educación Parvularid } \\
\text { y Prebásica }\end{array}$ & $\begin{array}{l}\text { Difusión y Gestión } \\
\text { Cultural }\end{array}$ & $\begin{array}{l}\text { Educación Intercul- } \\
\text { tural Bilingüe }\end{array}$ \\
\hline
\end{tabular}




\begin{tabular}{|c|c|c|c|}
\hline Área & 1990-1999 & 2000-2009 & $2010-2018$ \\
\hline \multirow{10}{*}{$\begin{array}{l}\text { Cultura y } \\
\text { Educación } \\
\text { (cont.) }\end{array}$} & Formación Docente & $\begin{array}{l}\text { Generación de Material } \\
\text { Radial y Televisivo }\end{array}$ & Becas Laborales \\
\hline & $\begin{array}{l}\text { Estrategias de Edu- } \\
\text { cación No Formal }\end{array}$ & $\begin{array}{l}\text { Fondo para la Difusión } \\
\text { de Iniciativas Locales }\end{array}$ & $\begin{array}{l}\text { Política Nacional de } \\
\text { Actividad Fisica }\end{array}$ \\
\hline & Lenguas Vernáculas & $\begin{array}{l}\text { Jardines Intercultu- } \\
\text { rales }\end{array}$ & $\begin{array}{l}\text { Turismo y Patrimonio } \\
\text { Cultural }\end{array}$ \\
\hline & Recursos Educativos & & $\begin{array}{l}\text { Apoyo al Campeo- } \\
\text { nato de Fútbol de } \\
\text { Pueblos Indigenas }\end{array}$ \\
\hline & $\begin{array}{l}\text { Recursos Promocio- } \\
\text { nales }\end{array}$ & & $\begin{array}{l}\text { Copa Americana de } \\
\text { Pueblos Indigenas }\end{array}$ \\
\hline & $\begin{array}{l}\text { Beca Residencia } \\
\text { Indigena }\end{array}$ & & $\begin{array}{l}\text { Deporte de } \\
\text { Participación Social }\end{array}$ \\
\hline & Hogares Indigenas & & $\begin{array}{l}\text { Rescate, Promo- } \\
\text { ción y Difusión de } \\
\text { Manifestaciones } \\
\text { Socioculturales } \\
\text { Mapuche }\end{array}$ \\
\hline & & & $\begin{array}{l}\text { Actividades Fisicas y } \\
\text { Juegos Mapuche }\end{array}$ \\
\hline & & & $\begin{array}{l}\text { Fomento y Difusión } \\
\text { de las Culturas y las } \\
\text { Artes de los Pueblos } \\
\text { Indigenas }\end{array}$ \\
\hline & & & $\begin{array}{l}\text { Parque Intercultural } \\
\text { Río Viejo }\end{array}$ \\
\hline \multirow[t]{5}{*}{$\begin{array}{l}\text { Gestión y } \\
\text { Desarrollo } \\
\text { Social }\end{array}$} & & Gestión Social Indigena & $\begin{array}{l}\text { Capacitación para } \\
\text { Comunidades y } \\
\text { Formación de Líderes }\end{array}$ \\
\hline & & Becas de Post-Grado & $\begin{array}{l}\text { Apoyo al Desarrollo } \\
\text { con Identidad }\end{array}$ \\
\hline & & $\begin{array}{l}\text { Formación Profesional } \\
\text { de Educación Intercul- } \\
\text { tural }\end{array}$ & $\begin{array}{l}\text { Mecanismos de Par- } \\
\text { ticipación Ciudadana }\end{array}$ \\
\hline & & & $\begin{array}{l}\text { Biodiversidad: } \\
\text { Conservación y } \\
\text { Restauración del } \\
\text { Patrimonio Natural y } \\
\text { Cultural }\end{array}$ \\
\hline & & & $\begin{array}{l}\text { Apoyo y Seguimiento } \\
\text { Consulta de Pueblos } \\
\text { Indigenas C-169 }\end{array}$ \\
\hline
\end{tabular}




\begin{tabular}{l|l|l|l}
\hline Área & 2000-2009 & 2010-2018 \\
\hline Gestión y & & & DS49 Subsidio \\
Desarrollo & & & Habitacional \\
Social (cont.) & & (Ptje. extra) \\
Concurso de \\
\end{tabular}

Nota: En ocasiones el titulo oficial del programa se ha abreviado en honor al espacio.

Fuente: Elaboración propia, en base a aquellos programas con información disponible sobre su año de creación. 
Figura 6. PRESUPUESTO ASIGNADO A PROGRAMAS PARA PUEBLOS INDÍGENAS, AÑO 2018
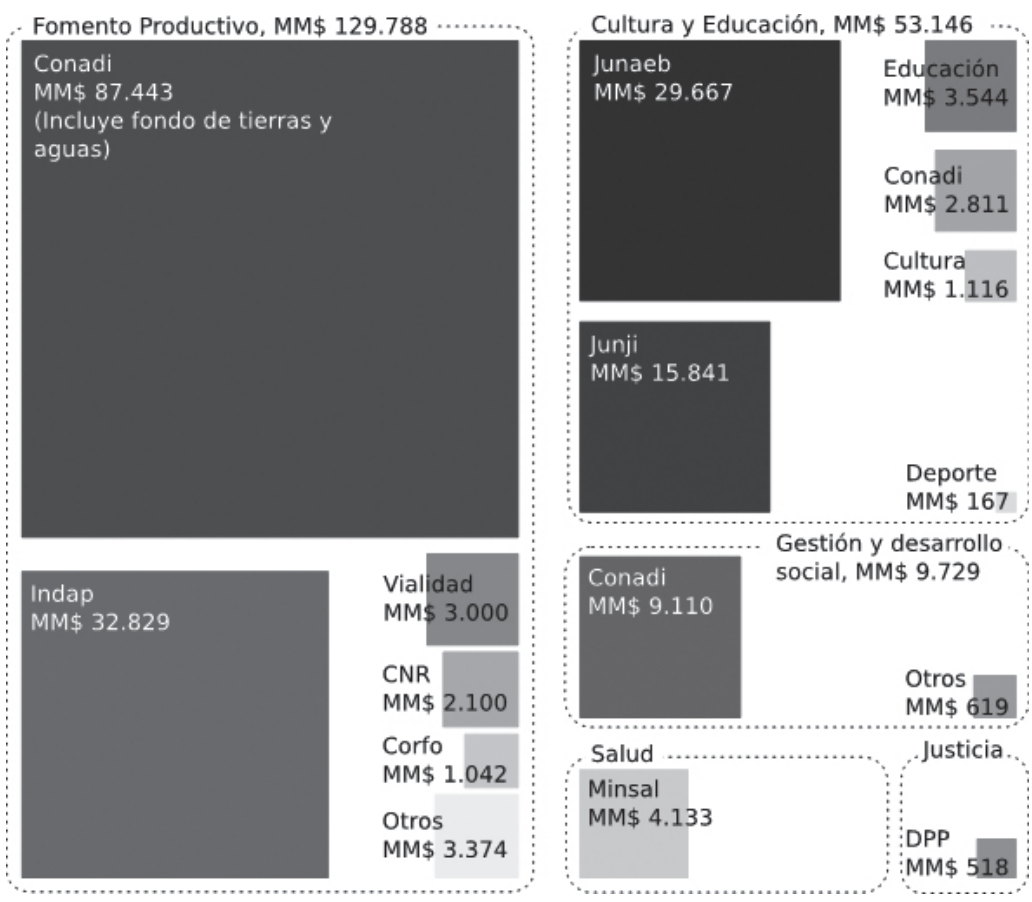

Deporte

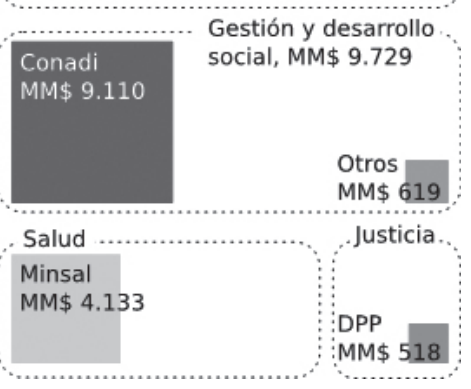

Fuente: Elaboración propia. Se consideran los programas destinados exclusivamente a pueblos indigenas, ya que, en el caso de los programas generales que priorizan o bonifican puntaje a miembros de pueblos indigenas, no es posible determinar qué parte de su presupuesto total se destina a ellos. Del total de programas estudiados, 110 clasifican para ser incluidos en este análisis. De ellos, 104 reportaron el presupuesto comprometido para 2018 y, por lo tanto, se reflejan en la figura (no reportan presupuesto: un programa en Salud, dos en Cultura y Educación, un programa en Justicia y dos programas en Fomento Productivo).

por ciento del gasto en el área) e Indap (25,3 por ciento), mientras que, en educación y cultura, más del 80 por ciento del gasto lo representan Junaeb (55,3 por ciento) y Junji (29,8 por ciento), con Conadi jugando un papel bastante menor en el área (5,3 por ciento del gasto total).

El área de gestión social y desarrollo representa el 4,9 por ciento del gasto total reportado, donde la Conadi posee la mayor fracción del mismo (93,6 por ciento) y ninguna de las otras instituciones representa más del 3 por ciento del gasto total.

Finalmente, en las áreas de Salud y Justicia todo el gasto que nos fue reportado está concentrado en una única institución para cada área: Ministerio de Salud y Defensoría Penal Pública (DPP), respectivamente. 
Tabla 5. RESUMEN DE INFORMES DE EVALUACIÓN SOBRE PROGRAMAS INDÍGENAS (DIPRES)

\begin{tabular}{|c|c|c|c|c|}
\hline $\begin{array}{l}\text { Programa / } \\
\text { Institución }\end{array}$ & $\begin{array}{l}\text { Linea de } \\
\text { evaluación }\end{array}$ & $\begin{array}{l}\text { Año de } \\
\text { protocolo }\end{array}$ & $\begin{array}{l}\text { Servicio } \\
\text { público }\end{array}$ & Calificación \\
\hline $\begin{array}{l}\text { Fondo de Tierras y } \\
\text { Aguas Indigenas }\end{array}$ & EPG & 1998 & Conadi & sin información* \\
\hline $\begin{array}{l}\text { Fondo de } \\
\text { Desarrollo } \\
\text { Indigena (FDI) }\end{array}$ & EPG & 1999 & Conadi & sin información ${ }^{\star *}$ \\
\hline $\begin{array}{l}\text { Programa } \\
\text { Fondo de Tierras y } \\
\text { Aguas Indigenas }\end{array}$ & $\mathrm{El}$ & 2001 & Conadi & $\begin{array}{l}\text { Modificaciones en el } \\
\text { diseño y/o procesos de } \\
\text { gestión interna }\end{array}$ \\
\hline $\begin{array}{l}\text { Becas Escolares } \\
\text { de Educación Bá- } \\
\text { sica y Media, Beca } \\
\text { Indigena }\end{array}$ & $\mathrm{El}$ & 2005 & Junaeb & $\begin{array}{l}\text { Modificaciones en el } \\
\text { diseño y/o procesos de } \\
\text { gestión interna }\end{array}$ \\
\hline $\begin{array}{l}\text { Fondo de Tierras y } \\
\text { Aguas Indigenas }\end{array}$ & EPG & 2008 & Conadi & $\begin{array}{l}\text { Modificaciones en el } \\
\text { diseño y/o procesos de } \\
\text { gestión interna }\end{array}$ \\
\hline $\begin{array}{l}\text { Fondo de } \\
\text { Desarrollo } \\
\text { Indigena: } \\
\text { Fomento } \\
\text { Económico }\end{array}$ & EPG & 2009 & Conadi & Rediseño sustantivo \\
\hline $\begin{array}{l}\text { Fondo de Desa- } \\
\text { rrollo Indigena: } \\
\text { Gestión Social }\end{array}$ & EPG & 2009 & Conadi & Rediseño sustantivo \\
\hline $\begin{array}{l}\text { Programa de De- } \\
\text { sarrollo Indigena }\end{array}$ & EPG & 2010 & Conadi & $\begin{array}{l}\text { Reemplazo íntegro o } \\
\text { finalización }\end{array}$ \\
\hline $\begin{array}{l}\text { Programa de De- } \\
\text { sarrollo Territorial } \\
\text { Indigena }\end{array}$ & $\mathrm{El}$ & 2012 & Indap & No aplica ${ }^{* \star *}$ \\
\hline $\begin{array}{l}\text { Aplicación del } \\
\text { Diseño Curricular } \\
\text { y Pedagógico } \\
\text { Intercurricular } \\
\text { Bilingüe }\end{array}$ & EPG & 2013 & Conadi & Desempeño insuficiente \\
\hline $\begin{array}{l}\text { Programa de Edu- } \\
\text { cación Intercultu- } \\
\text { ral Bilingüe }\end{array}$ & EPG & 2013 & $\begin{array}{l}\text { Subsecretaría } \\
\text { de Educación }\end{array}$ & Desempeño insuficiente \\
\hline Hogares Indigenas & EPG & 2014 & Junaeb & $\begin{array}{l}\text { Resultados no } \\
\text { demostrados }\end{array}$ \\
\hline
\end{tabular}




\begin{tabular}{lcccl}
\hline $\begin{array}{l}\text { Programa / } \\
\text { Institución }\end{array}$ & $\begin{array}{c}\text { Línea de } \\
\text { evaluación }\end{array}$ & $\begin{array}{c}\text { Año de } \\
\text { protocolo }\end{array}$ & $\begin{array}{l}\text { Servicio } \\
\text { público }\end{array}$ & Calificación \\
\hline $\begin{array}{l}\text { Programa Resi- } \\
\text { dencia Indigena }\end{array}$ & EPG & 2014 & Junaeb & $\begin{array}{l}\text { Resultados no } \\
\text { demostrados }\end{array}$ \\
\hline $\begin{array}{l}\text { Programa Chile } \\
\text { Indiggena }\end{array}$ & EPG & 2018 & Conadi & Mal desempeño*** \\
\hline
\end{tabular}

Notas:

* Este programa aparece sin información debido a que la metodología seguida a la fecha de realización no coincide con la actualmente en uso. El informe final señala, entre otras cosas, que no es posible determinar el grado de cumplimiento del programa por carecer éste de metas definidas.

** Este programa aparece sin información debido a que la metodología seguida a la fecha de realización no coincide con la actualmente en uso. El informe final señala que el programa presentaba problemas en su diseño, organización y gestión, y que no fue posible cuantificar indicadores sobre la eficacia y cumplimiento de las metas debido a la falta de información sobre los beneficiarios, asi como tampoco sobre la eficiencia en la ejecución presupuestaria. La recomendación fue mantener el programa pero someterlo a un rediseño global.

*** Este programa aparece bajo la categoría "no aplica" debido a que la evaluación de 11 programas del Indap no fue factible de realizar por problemas metodológicos y logísticos, incluyendo el desconocimiento respecto a las características de los beneficiarios y el no contar con acceso a bases de datos de potenciales beneficiarios de Indap que no sean parte de los usuarios.

**** A partir del año 2018, se redefinió la clasificación de los programas en cuatro categorias: buen desempeño, desempeño medio, desempeño bajo y mal desempeño.

Fuente: Sistema de Evaluación y Control de Gestión (Dipres 2018).

\section{EVALUACIONES SOBRE LOS PROGRAMAS INDÍGENAS}

Si bien la oferta de programas indígenas que proveen distintos ministerios y servicios se ha ampliado en el tiempo, las evaluaciones existentes son preocupantes. Al mirar en conjunto las evaluaciones de programas que lleva a cabo la Dirección de Presupuestos (Dipres) con las auditorías que hace la Contraloría General de la República (CGR) y los resultados de las comisiones investigadoras de la Cámara de Diputados, se da cuenta de una realidad compleja, en que abunda no sólo la inefectividad de las políticas públicas, sino que también los problemas administrativos.

En primer lugar, de los catorce programas indígenas que han sido evaluados por la Dipres, ninguno ha obtenido resultados positivos. Las recomendaciones tanto de las evaluaciones de impacto de programas 
(EI) como de las evaluaciones de programas gubernamentales (EPG ${ }^{25}$ justamente apuntan a lo opuesto: sugieren la necesidad de llevar a cabo modificaciones mayores, rediseño sustantivo, reemplazo íntegro, e incluso se evidencian programas que no demuestran tener resultados (ver tabla 6).

Los informes de evaluación dan cuenta de que, si bien se valora su existencia en cuanto buscan atender problemas de una población altamente vulnerable, los programas creados no responden a una política estratégica coordinada. Varios de los programas evaluados han surgido a partir de situaciones coyunturales y están sujetos a constantes modificaciones por parte de las autoridades. En el proceso de diseño no se tiene claridad sobre los potenciales beneficiarios, abundan los problemas de gestión (acentuados por los constantes cambios) y no se cuenta con mediciones de eficacia y calidad de los programas. Las evaluaciones también dan cuenta de que en aquellos programas en que participan varias instituciones públicas no existe coordinación inter o intrainstitucional. ${ }^{26}$ Cabe hacer presente además que, salvo excepciones como el Programa Chile Indígena, las evaluaciones no se han realizado recientemente, a pesar de que los programas continúan implementándose e incluso, como en el caso del Fondo de Tierras y Aguas, ocupan la mayor parte del presupuesto de la Conadi y de la política indígena.

En todo caso, la última evaluación de un programa indígena es ilustrativa de las deficiencias persistentes detectadas. En el primer semestre de 2018 se llevó a cabo la evaluación de la componente "Apoyo al desarrollo con identidad", de Chile Indígena, programa de la Conadi. Si bien se destaca que la identificación del problema que busca abordar es correcto, en su diseño, implementación y evaluación presenta una serie de debilidades. Señala el informe:

25 Las evaluaciones de impacto (EI) se centran en evaluar los resultados intermedios y finales de los programas a través de la utilización de metodologías cuasiexperimentales. Su propósito es cuantificar cómo son afectadas las variables o condiciones que generan la necesidad de política pública por los programas específicos. Las evaluaciones de programas gubernamentales (EPG), por otra parte, evalúan la consistencia de los objetivos y diseño de un programa con su organización, gestión y resultados a nivel de producto (cobertura, focalización, satisfacción, entre otros).

${ }^{26}$ Para mayores ejemplos sobre el resultado de las evaluaciones de la Dipres, ver Aninat (2017). 
Considerando que el problema público persiste, la estrategia de intervención es adecuada y que, si bien no fue posible probar los resultados del estudio complementario, éste arroja señales de que el programa ha generado mejoras en las capacidades de las comunidades participantes, se justifica la continuidad; no obstante, y tomando en cuenta las debilidades planteadas, se recomienda un rediseño que recoja los aprendizajes, tanto de los Programas Orígenes como del Chile Indígena, incorporando modificaciones sustantivas de acuerdo a las recomendaciones. (Dipres 2018, 18)

El año 2018 también se incluyeron programas indígenas en la evaluación ex ante de programas públicos no sociales de la Dipres. ${ }^{27}$ Un caso dramático es el Indap. En primer lugar, la revisión del nuevo programa Mejoramiento de Suelos en Territorios Indígenas señala que éste no identifica adecuadamente la población potencial ni proyecta el número de beneficiarios y tampoco formula indicadores para medir su propósito, presentando problemas de metodología para validar los valores de los indicadores a usarse. Pero más dramático es el caso de la revisión del diseño del Programa de Desarrollo Territorial Indígena (PDTI), un programa relevante dentro del panorama actual de políticas indígenas. La conclusión de la evaluación es que falla en los cuatro pilares analizados: no tiene un adecuado diagnóstico del problema, no identifica su población potencial, no es potencialmente medible y no detalla sus componentes ni formula articulaciones necesarias.

$\mathrm{Si}$ a estas evaluaciones agregamos los problemas detectados en los informes de auditoría de la CGR y de las comisiones investigadoras de la Cámara de Diputados sobre instituciones y programas indígenas, el panorama aparece bajo una luz aún más desalentadora. El funcionamiento del Fondo de Tierras y Aguas de la Conadi ha sido objeto de múltiples comisiones investigadoras, todas las cuales han dado cuenta de los diversos problemas existentes, que ya han pasado a ser recurrentes (Comisión Investigadora 2015; 2016, 111). Estos problemas coinciden con la ausencia de controles administrativos y la deficiente gestión detectadas por la CGR en diversos programas indígenas, incluyendo los de compra de tierras (ver, por ejemplo, CGR 2011; 2016).

27 Ver informes en http://www.dipres.gob.cl/597/w3-multipropertyvalues-24043-24321.html\#instrumento_gestion_3/. 
Por otra parte, si bien en nuestro país son escasos los estudios que incluyen una revisión integral y comprehensiva de los programas que involucra la política indígena, existen algunos ejemplos que dan cuenta de problemas recurrentes de los programas en materia indígena. ${ }^{28}$

En el año 2011, un estudio de la Food and Agriculture Organization de las Naciones Unidas (FAO), el Fondo para el Logro de los Objetivos de Desarrollo del Milenio (FLODM) y Segpres incluyó un análisis integral de los programas e instrumentos para los pueblos indígenas en Chile. Las conclusiones de dicho estudio revelaron tanto una manifiesta falta de coordinación entre los servicios públicos, así como la inexistencia de un organismo que vele por la coherencia de los programas pertinentes (FAO et al. 2012a). Como parte de dicho estudio, se efectuó un taller para estudiar la política indígena pertinente, cuyo informe incluye una agrupación de nudos críticos en cuatro aspectos: (i) problemas con las normativas sectoriales, (ii) problemas de recursos, (iii) problemas de gestión o coordinación institucional y (iv) problemas de información. Es interesante, además, que el informe explicita también cómo se evidencian estas dificultades al intentar materializar planes integrales de inversión comunitaria a nivel territorial (de gobierno regional). Finalmente, la primera recomendación en materia institucional es contar con una mejor definición en la conducción de la política indígena, que permita lograr la integralidad, de manera de tener claridad en los lineamientos y definir una agenda transversal que sea medible (FAO et al. 2012b).

Si se quiere avanzar en una política nacional indígena, como es el objetivo propuesto explícitamente para la nueva institucionalidad, es necesario que su mayor formalidad y periodicidad vayan acompañadas también de mayor responsabilidad respecto de los compromisos asumidos. Ello requiere, en primer lugar, que se haga cargo del panorama actual sobre el cual se instala, abandonando la mirada fragmentaria que ha caracterizado su desarrollo.

Para lograr lo anterior, es crucial la evaluación que se haga no sólo de los programas en particular, sino que también del mapa completo

${ }^{28}$ El Banco Integrado de Programas Sociales del Ministerio de Desarrollo Social incluye una gran cantidad de programas para la población indígena; sin embargo, está limitado sólo a los programas catalogados como sociales, dejando fuera los sectores económicos y ministerios que tienen alta relevancia en este ámbito (como el Ministerio de Agricultura y el Ministerio de Economía). 
o, al menos, de áreas temáticas, considerando explícitamente las interacciones entre los elementos que las conforman. Frente al riesgo de políticas nacionales sucesivas en que la continuidad impida dilucidar la efectividad de lo comprometido, es crucial, también, darle un mayor rol a la evaluación. La experiencia internacional muestra la importancia que ella puede tener para informar cambios y mejoras en la implementación de la política indígena, especialmente cuando se hace mediante evaluaciones más holísticas que consideran la totalidad del sistema.

Los ejemplos del Ministerio de Hacienda en Australia y de Coneval en México, aludidos precedentemente, podrían replicarse en el ámbito de evaluación que lleva a cabo la Dipres en Chile. Una mirada general a la manera de implementar sus programas podría dar muchas luces sobre los problemas persistentes de la Conadi. Las evaluaciones que se han llevado a cabo pierden de vista que hay problemas que se replican muchas veces y que no son propios del programa en cuestión, sino que de la institución y de su capacidad de implementar, desplegar, aprender y rediseñar programas. ${ }^{29}$ Por ejemplo, temas que dicen relación con la estructura organizacional, la gestión de los programas, la rendición de cuentas, el monitoreo del uso de los recursos públicos, los mecanismos de seguimiento y la medición de satisfacción de los beneficiarios.

\section{DESAFIOOS INSTITUCIONALES PARA UNA POLÍTICA INDÍGENA}

Frente a esta realidad, cabe preguntarse entonces cómo hacerse cargo de una supuesta política indígena que, en la práctica, se traduce en programas en los que abundan la dispersión, la incoherencia y la falta de efectividad. Esta pregunta es aún más atingente considerando la discusión sobre una nueva institucionalidad de y para los pueblos indí-

${ }^{29}$ Por lo mismo, si se llegase a crear en Chile una agencia de evaluación de las políticas públicas, ésta debiese tener las facultades para hacer evaluaciones comprehensivas de las políticas públicas, y no limitarla a la evaluación de programas aislados. Crucial es también la entrega de dichos informes al Congreso, de manera que iluminen la discusión política y presupuestaria y éste pueda cumplir su rol fiscalizador provisto de contenido. Ver, por ejemplo, la propuesta sobre institucionalizar la Comisión de Productividad y extender sus facultades estableciendo la Agencia de Productividad y Evaluación (Comisión de Modernización del Estado (CEP) 2018). 
genas. ¿Qué herramientas debiera tener la futura institucionalidad para construir una política indígena propiamente tal?

En la propuesta de creación del Ministerio de Pueblos Indígenas (Boletín 10.687-06), se apunta a que éste tenga el mandato legal para generar e implementar una política indígena coordinada y coherente. Como hemos evidenciado, el mandato legal por sí sólo no es garantía de que ello ocurra. Tal como lo muestra la evidencia presentada y la política pública generada desde la creación de la Conadi, incluso bajo la supervigilancia de un ministerio coordinador como es el MDS.

Por supuesto, puede argumentarse que el hecho de que actualmente sea un servicio público el que deba coordinar tal cantidad de ministerios y servicios, dada su relativamente baja jerarquía, hace más difícil su tarea dentro del aparato estatal, especialmente cuando la labor de diseño y ejecución están concentradas en el mismo órgano. Al establecer un ministerio, dichas labores se separan, pero su sola conformación no asegura su éxito. El mandato legal debe ir acompañado de herramientas que permitan hacer efectiva dicha coordinación. A continuación se discuten algunas de ellas. ${ }^{30}$

Como se demostró en la sección IV, la dificultad mayor es claramente la coordinación intersectorial. Una de las herramientas más utilizadas — aunque no por eso efectiva — para paliar la descoordinación al interior del aparato estatal es la creación de comités interministeriales. ${ }^{31}$ Esta herramienta se encuentra también dentro de las propuestas para una futura institucionalidad, aunque con atribuciones extensivas a un ámbito distinto (resolver sobre la pertinencia de consultas indígenas). Ahora bien, dado que el panorama actual se ha producido, en parte,

${ }^{30}$ Las herramientas a las que se hace alusión a continuación están contempladas en los citados proyectos de ley que crean el Ministerio de Pueblos Indígenas, los Consejos de Pueblos Indígenas y el Consejo Nacional de Pueblos Indígenas. Dado que dichos proyectos están actualmente en debate parlamentario, es posible que estén sujetos a cambios. Sin embargo, se discuten los principios que subyacen en dichos proyectos y no los articulados específicos.

31 Como señala Pliscoff $(2018,197)$ : "La creación de comités o comisiones interministeriales puede ser un esfuerzo interesante para articular la oferta estatal, pero, de acuerdo a la información entregada por los propios ministerios, todo indica que existe un número muy alto de estas instancias sin que exista claridad respecto de su verdadero efecto. A esto se suma el diseño de gestión interna de cada ministerio, el cual no está pensado para articular toda la oferta de los servicios que forman parte de su estructura, organizando todos los instrumentos de gestión en torno a una oferta pública coherente". 
bajo la existencia de un Comité de Asuntos Indígenas, es importante apuntar a que el futuro comité, creado ahora por ley, sea efectivo en la coordinación y coherencia de una política nacional indígena.

Por lo anterior, sería recomendable dotar a este comité interministerial no sólo de un mandato y de herramientas de coordinación, sino también de un mecanismo de rendición de cuentas, más allá de las que se establecen en relación con la consulta indígena. Ello, además, debe ir de la mano de medidas complementarias que incentiven la coordinación interinstitucional.

Por ejemplo, la publicación de informes que analizan la oferta programática indígena en el Estado es una herramienta utilizada a nivel comparado. En Chile el MDS publica anualmente un Informe de Política Social, pero no tiene como único foco el tema indígena ni es comprehensivo de ésta, al dejar fuera los ministerios económicos y los programas desarrollados a nivel regional. Podrían crearse informes con análisis multisectoriales y que se hicieran públicos en actos formales de publicación y entrega; por ejemplo, a los pueblos indígenas y al Congreso. La experiencia comparada señalada en la sección III da luces respecto de ejemplos que pueden resultar útiles para ello.

Otra medida complementaria podría ser el fomento a la coordinación por la vía presupuestaria. Además de los convenios de programación, podrían avanzarse instrumentos de focalización territorial del presupuesto; por ejemplo, a nivel de los gobiernos regionales. ${ }^{32}$

Quizás una pregunta no del todo resuelta, y para la que deberá encontrarse algún equilibrio en la práctica, dice relación con la superposición que pueda existir entre un futuro Ministerio de Pueblos Indígenas y el MDS en aquellos programas que son tanto sociales como indígenas. El que existan dos ministerios que tienen como parte de su misión la coordinación intersectorial podrá generar discrepancias respecto de la visión de ciertos programas y podrá atentar contra aquello que se busca: la coordinación y coherencia de una política intersectorial.

32 Además, la Ley 21.074, de fortalecimiento de la regionalización del país, regula legalmente el cumplimiento de los convenios de programación y permite que los gobiernos regionales puedan suscribirlos a nivel territorial con una o más municipalidades o con uno o más servicios públicos, bajo determinadas condiciones. Con ello se abrirá entonces una vía de colaboración presupuestaria mucho más fuerte a nivel regional y que puede cobrar especial importancia en los temas que son intersectoriales, como la política indígena. 


\section{DISCUSIÓN Y CONCLUSIONES}

Desde el retorno de la democracia cada gobierno ha realizado esfuerzos para generar una política indígena que apunte a reparar la deuda histórica contraída con dichos pueblos y resolver los múltiples problemas que los afectan. ${ }^{33} \mathrm{Un}$ análisis de los anuncios realizados, informes generados y políticas propuestas muestra que, con pocas excepciones, se han enunciado cada vez los mismos propósitos y se ha planteado el uso del mismo tipo de herramientas. Sin embargo, la situación de los pueblos indígenas está lejos de haber experimentado una mejoría significativa en el periodo. En efecto, si bien la pobreza y la vulnerabilidad se han reducido en esa población, ambas han mejorado más lentamente que el resto de la sociedad beneficiaria de programas generales, lo que muestra que la política focalizada no ha sido efectiva en reducir las brechas entre ambos grupos.

Más aún, después de un importante esfuerzo en la generación de una significativa oferta de política pública en las áreas de cultura y educación, los pueblos indígenas continúan experimentando un notorio retroceso en el uso y conocimiento de su lengua, su principal marcador de pertenencia, como se señaló en la sección II.

Dado lo anterior, es pertinente preguntarse por qué las políticas indígenas parecen tener resultados limitados y no alcanzar los objetivos para las que fueron formuladas. En este trabajo intentamos aproximarnos a una respuesta a esta interrogante a partir de dos fuentes de información. Primero, una revisión comprehensiva de los programas estatales focalizados en la población (reportado por los propios servicios y solicitado mediante Ley de Transparencia), incluyendo información de sus acciones, población objetivo, mecanismo de focalización y articulaciones. Y segundo, un análisis de las evaluaciones de programas realizadas por la Dipres.

Nuestro análisis de la oferta programática efectiva pone en evidencia una notable falta de coordinación entre las instituciones ejecutoras de las distintas iniciativas que rara vez articulan entre ellas las acciones que implementan. Existen, indudablemente, algunas instancias de coordinación que parecen bien pensadas y funcionales (por ejemplo, la

${ }^{33}$ Sobre la deuda histórica, ver el informe de la Comisión Verdad Histórica y Nuevo Trato (2003). 
Mesa de Turismo Indígena), pero, incluso entre programas altamente relacionados, las reparticiones encargadas de su funcionamiento no reportan articulaciones cuya existencia pareciera obvia. Esto es especialmente cierto en el caso de programas en el área de cultura y educación.

En un caso en particular, el mismo programa, implementado en los distintos servicios de salud, reporta coordinaciones locales pero no centrales e, incluso, declara grupos objetivos distintos (población indígena, población rural o población general). Ello refleja que incluso la coordinación al interior de un mismo ministerio no está funcionando como sería esperable.

Lo anterior resulta algo sorprendente, dado que, al menos en el caso de programas sociales, existe, además de la Conadi, un Comité de Ministros, ambos encargados explícitamente de realizar la labor de coordinación de la oferta, junto a un ministerio — el MDS - como ente coordinador del tema indígena.

La evaluación de los programas realizada por la Dipres no arroja mejores resultados. En ninguna ocasión ha alcanzado la calificación positiva. Por el contrario, si bien se considera positivamente la existencia de los programas, por cuanto los problemas identificados existen y afectan con mayor intensidad a la población indígena — de suyo más vulnerable-, se señala que las iniciativas en general no cuentan con un diagnóstico acabado, no responden a una visión de política estratégica que les provea un lineamiento central y coordinado, y, en ocasiones, ni siquiera cuentan con una descripción acabada de sus potenciales beneficiarios. A esto se suman problemas en la gestión e implementación y de coordinación entre las distintas instituciones que pueden estar involucradas en la ejecución.

El desarrollo de una política indígena ha sido descrito en la literatura como un wicked problem debido a su complejidad, característica multicausal y abundante interdependencia. La recomendación actual es, entonces, adoptar un análisis más bien integrado (whole of government) en que prime la acción coordinada de los distintos organismos que intervienen en su desarrollo e implementación. En este sentido, la experiencia comparada muestra que contar con un órgano coordinador, que genere lineamientos en la forma de una política, información de seguimiento y sea responsable de rendir cuentas respecto a la implementación y evaluación de la política en su conjunto, puede ser un diseño deseable. 
La institucionalidad hoy en discusión en Chile propone la creación de un Ministerio de Pueblos Indígenas que tendría, fundamentalmente, la misión de generar e implementar una política indígena coordinada y coherente. Sin embargo, es posible dudar de que esto por sí solo baste para lograr el objetivo. La evidencia es que la descoordinación actual de la oferta programática fue generada bajo la existencia de la Conadi, organismo que tiene - al menos nominalmente - un mandato coordinador similar al que tendrá dicho ministerio, en el que su ineficacia no puede culparse sólo a un problema de jerarquía. En otras palabras, mayor jerarquía en la coordinación no asegura que ésta se vaya a realizar efectivamente.

Debe considerarse, además, que el Ministerio de Pueblos Indígenas no existirá en la nada. Una vez creado, deberá hacerse cargo de la situación actual, la que incluye una oferta ampliamente fragmentada e inorgánica. La sola labor de ordenar y coordinar los programas existentes requerirá de un importante esfuerzo. Ésta es la base sobre la que deben considerarse los objetivos propios de la nueva institucionalidad, lo que configura un desafío importante.

En paralelo, se considera la creación de un comité interministerial para favorecer la coordinación entre instituciones, además de decisiones respecto de la procedencia de cada consulta indígena. $\mathrm{Al}$ respecto, la experiencia chilena no parece ser demasiado convincente. En los últimos 50 años se han creado más de cien comités interministeriales, sin que hayan demostrado ser demasiado efectivos como instancias de coordinación. Sería importante no sólo dotar a este comité de un propósito estipulado en la ley, sino también someter a la orgánica completa a un proceso de rendición de cuentas que permita evaluar su gestión. Por cierto, los Consejos de Pueblos Indígenas y el Consejo Nacional de Pueblos Indígenas serán contrapartes activas en hacerles seguimiento a las políticas comprometidas.

La experiencia internacional muestra que la generación de informes que sistematicen y analicen la oferta permite que se haga seguimiento de los propósitos de la institucionalidad. Complementario a esto, evaluaciones comprehensivas del sistema y su funcionamiento que pongan en evidencia los propósitos, falencias de diseño y esfuerzos (o falta de) coordinación entre instituciones permiten tener una mejor visión de cómo se avanza en la consecución de los objetivos que originan la oferta. 
Es interesante ver cómo estos informes son útiles para los propios organismos públicos en el diseño, implementación y ejecución de sus políticas. Es decir, su foco no es únicamente el control, sino también la gestión interna del propio aparato estatal. Las revisiones periódicas sistemáticas, presentadas formal y públicamente, son herramientas ordenadoras del actuar de las diversas instituciones públicas que participan en políticas intersectoriales.

Creemos que informes similares al presentado en este documento, generados regularmente, pueden contribuir no sólo en el diagnóstico, sino también en el control respecto del avance de una política indígena efectiva. Ello ocurrirá con mucha mayor efectividad si es que los informes emanan del propio Estado, tal como ocurre en otros países.

En cualquier caso, ello debe ir de la mano de otros mecanismos que incentiven la colaboración. A la luz de las reformas legales recientemente aprobadas sobre descentralización y regionalización, existirá espacio para mayor colaboración presupuestaria a nivel territorial. Potenciar instrumentos como los convenios de programación es también una alternativa para alinear a los distintos servicios públicos que intervienen en la política indígena.

Por supuesto, nada asegura que mayor coordinación implique necesariamente mayor efectividad de los programas implementados. Por lo mismo, es necesario poner especial ahínco en la importancia de la evaluación, especialmente a la luz de los resultados de las evaluaciones ya existentes de distintos programas indígenas. No sólo es necesario más evaluaciones, sino también que éstas puedan incluir miradas más globales, ya sea sobre una institución que ejecuta distintos programas o sobre una política compuesta por una serie de programas. Esta mirada puede contribuir a alertar sobre problemas recurrentes que requieren abordarse de forma sistemática. Parece relevante, incluso más allá de la política indígena, considerar la creación de una futura agencia de evaluación.

Las políticas públicas en materia indígena son, por esencia, multisectoriales. Y si bien abordan los distintos ámbitos que son parte de la realidad de los pueblos indígenas, en la práctica han encarnado los peligros de la multisectorialidad: la dispersión, la fragmentación, la incoherencia y la ausencia de una estrategia general. Frente a esta realidad, se hace aún más necesario que una futura institucionalidad cuente con herramientas para una política indígena coordinada y efectiva. 


\section{REFERENCIAS}

Aninat, Isabel. 2017. "Confianza y el pueblo mapuche: análisis desde la perspectiva de desempeño institucional". En El pueblo mapuche en el siglo XXI. Propuestas para un nuevo entendimiento entre culturas en Chile, editado por Isabel Aninat, Verónica Figueroa y Ricardo González, 197-226. Santiago: Centro de Estudios Públicos.

Australian Public Service Commission. 2007. "Tackling wicked problems. A public policy perspective". Gobierno de Australia. https://www.apsc.gov.au/tacklingwicked-problems-public-policy-perspective/.

Cámara de Diputados de Chile. 2015. Informe de la "Comisión especial investigadora sobre compras de tierras para personas y comunidades indígenas, entre los años 2011 y 2013". https://www.camara.cl/trabajamos/comision ficha.aspx?prmID $=819$

2016. Informe de la "Comisión especial investigadora de los actos de Gobierno en relación con la situación de inseguridad que se vive en la Región de La Araucania". https://www.camara.cl/pdf.aspx?prmID=80575\&prmTIPO =DOCUMENTOCOMISION $/$.

Centro de Estudios Interculturales e Indígenas (CIIR). 2017. Estudio longitudinal de relaciones interculturales. Santiago.

Centro de Estudios Públicos. 2006. Encuesta CEP. Los mapuche rurales y urbanos hoy. Mayo 2006. Santiago: Centro de Estudios Públicos.

- 2016. Encuesta CEP. Los mapuche rurales y urbanos hoy. Marzo - Mayo 2016. Santiago: Centro de Estudios Públicos.

. 2018. Comisión de Modernización del Estado.

Cerda, Rodrigo. 2017. "Situación socioeconómica reciente de los mapuches: 20092015”. En El pueblo mapuche en el siglo XXI. Propuestas para un nuevo entendimiento entre culturas en Chile, editado por Isabel Aninat, Verónica Figueroa y Ricardo González, 405-434. Santiago: Centro de Estudios Públicos.

Christensen, T. \& P. Lægreid. 2007. "The Whole-Of-Government Approach to Public Sector Reform”. Public Administration Review 67 (6): 1059-1066.

Comisión Asesora en Temas de Desarrollo Indígena. 1999. Informe Comisión Asesora en Temas de Desarrollo Indigena. Santiago de Chile: Mideplan.

Comisión Asesora Presidencial de La Araucanía. 2016. Informe Comisión Asesora Presidencial de La Araucanía. Santiago: Gobierno de Chile. https://prensa. presidencia.cl/lfi-content/otras/informes-comisiones/Informe_AP_Final.pdf/.

Comisión Asesora sobre Política Indígena Urbana. 2006. Propuesta para la generación participativa de una política indígena urbana. Informe de la Comisión Asesora. Santiago: Mideplan. http://www.ministeriodesarrollosocial. gob.cl/btca/txtcompleto/polit.indigenasurbanos.pdf/.

Comisión de Modernización del Estado (CEP). 2018. Un Estado para la ciudadanía. Informe de la Comisión de Modernización del Estado. Santiago: Centro de Estudios Públicos. 
Comisión Verdad Histórica y Nuevo Trato con los Pueblos Indígenas. 2003. Informe de la Comisión Verdad Histórica y Nuevo Trato con los Pueblos Indigenas. Santiago: Gobierno de Chile. https://bibliotecadigital.indh.cl/ handle/123456789/268E/.

Consejo Nacional de Evaluación de la Política de Desarrollo Social (Coneval). 2012. "Evaluación integral de las dependencias de la administración pública federal asociadas al desarrollo social 2011-2012”. Comisión Nacional para el Desarrollo de los Pueblos Indígenas. México, D.F. https://www.coneval.org. mx/Informes/Evaluacion/Integrales/Integrales\%202011-2012/EI_CDI.pdf/.

2013. "Evaluación integral del desempeño de los programas federales y acciones dirigidas a la población indígena 2010-2013”. México, D.F. https:// www.coneval.org.mx/Informes/Evaluacion/Integrales/Integrales\%2020122013/01_EI_INDIGENAS.pdf/.

Contraloría General de la República (CGR). 2011. Informes de auditoría. Santiago: Gobierno de Chile.

2016. Informes de auditoría. Santiago: Gobierno de Chile.

Department of Finance and Deregulation. 2010. "Strategic Review of Indigenous Expenditure. Report to the Australian Government (Released under FOI Act)". Gobierno de Australia. https://www.finance.gov.au/sites/default/files/foi_1027 strategic_review_indigenous_expenditure.pdf/.

Department of the Prime Minister and Cabinet. 2018. "Closing the gap. Prime Minister's Report 2018”. Gobierno de Australia. https://www.pmc.gov.au/ sites/default/files/publications/ctg-report-2018.pdf/.

De Cea, Maite \& Camila Peralta. 2018. "Consulta indígena en dos sectores del aparato estatal en Chile: Desarrollo Social y Cultura”. Culturales 6, e341.

Dirección de Presupuestos (Dipres). 2013. "Informe final: Programa Aplicación Diseño Curricular y Pedagógico Intercultural Bilingüe, Conadi, MDS y Programa Educación Intercultural Bilingüe, Mineduc". División de Control de Gestión de Dipres. Gobierno de Chile.

- 2018. "Resumen ejecutivo: Evaluación programas gubernamentales: Programa Chile Indígena, Ministerio de Desarrollo Social, Corporación Nacional de Desarrollo Indígena”. División de Control de Gestión de Dipres. Gobierno de Chile.

Donoso, Sebastián \& Camila Palacios. 2018. "Pueblos indígenas y reconocimiento constitucional: aportes para un debate". Temas de la Agenda Pública 103. Centro de Políticas Públicas UC.

FAO, FLODM \& Segpres. 2012a. Revisión de programas e instrumentos públicos para el mundo indigena en Chile.

2012b. "Informe del taller nacional: Hacia una política indígena pertinente". 5 y 6 enero, Santiago.

Gobierno de Chile. 2004. Política de nuevo trato con los pueblos indígenas. Derechos indigenas, desarrollo con identidad y diversidad cultural. Santiago.

2008. Re-Conocer. Pacto social por la multiculturalidad. Santiago.

2010. Plan Araucanía. Invirtiendo en personas y oportunidades. Santiago. 
. 2016. Plan de reconocimiento "Desarrolla Araucanía Intercultural". Santiago.

Imilán, Walter. 2017. "Ser mapuche en la ciudad: Perspectivas sobre migración, etnificación y cultura". En El pueblo mapuche en el siglo XXI. Propuestas para un nuevo entendimiento entre culturas en Chile, editado por Isabel Aninat, Verónica Figueroa y Ricardo González, 79-110. Santiago: Centro de Estudios Públicos.

Loncon, Elisa. 2017. "Políticas públicas de lengua y cultura aplicada al mapuzugun”. En El pueblo mapuche en el siglo XXI. Propuestas para un nuevo entendimiento entre culturas en Chile, editado por Isabel Aninat, Verónica Figueroa y Ricardo González, 275-404. Santiago: Centro de Estudios Públicos.

Ministerio de Desarrollo Social. 2017a. Informe de desarrollo social. Santiago: Unidad de Comunicaciones Ministerio de Desarrollo Social.

- 2017b. Informe Final: Sistematización Proceso de Consulta Constituyente Indigena. Santiago: Unidad de Comunicaciones Ministerio de Desarrollo Social.

Ministerio de Desarrollo Social, Intendencia de La Araucanía y Ministerios Sectoriales. 2018. "Acuerdo Nacional por el desarrollo y la paz en La Araucanía (2018)". 24 de septiembre.

O’Flynn, Janine. 2018. "La experiencia australiana en las reformas del sector público". En Un Estado para la ciudadanía. Estudios para su modernización, editado por Isabel Aninat y Slaven Razmilic, 91-152. Santiago: Centro de Estudios Públicos.

Pliscoff, Cristián. 2018. "La estructura del Poder Ejecutivo en Chile: historia, presente y reflexiones para el futuro". En Un Estado para la ciudadanía. Estudios para su modernización, editado por Isabel Aninat y Slaven Razmilic, 153-211. Santiago: Centro de Estudios Públicos.

Productivity Commission for the Steering Committee for the Review of Government Service Provision. 2016. Overcoming indigenous disadvantage. Key indicators. Gobierno de Australia.

Te Puni Kokiri. 2014. "Effectiveness for Maori Measurement and Reporting Framework: A Resource for State Sector Agencies". Gobierno de Nueva Zelandia.

—. 2017. "Better Public Services Results for Maori 2011-2016". Gobierno de Nueva Zelandia.

Valenzuela, Eduardo \& Daniela Aranis. 2018. "Identidad mapuche en tiempos de urbanización”. Estudios Públicos 149: 311-323.

Zúñiga, Fernando \& Aldo Olate. 2017. "El estado de la lengua mapuche, diez años después". En El pueblo mapuche en el siglo XXI. Propuestas para un nuevo entendimiento entre culturas en Chile, editado por Isabel Aninat, Verónica Figueroa y Ricardo González, 343-374. Santiago: Centro de Estudios Públicos. EP 